\title{
Decadal Sea Level Variations in the Indian Ocean Investigated with HYCOM: Roles of Climate Modes, Ocean Internal Variability, and Stochastic Wind Forcing*
}

\author{
YUANLONG LI AND WEIQING HAN \\ Department of Atmospheric and Oceanic Sciences, University of Colorado, Boulder, Colorado
}

(Manuscript received 7 April 2015, in final form 24 June 2015)

\begin{abstract}
In this study decadal ( $\geq 10 \mathrm{yr}$ ) sea level variations in the Indian Ocean (IO) during 1950-2012 are investigated using the Hybrid Coordinate Ocean Model (HYCOM). The solution of the main run agrees well with observations in the western-to-central IO. Results of HYCOM experiments reveal large spatial variations in the mechanisms of decadal sea level variability. Within the tropical IO (north of $20^{\circ} \mathrm{S}$ ), decadal sea level variations achieve maximum amplitude in the south IO thermocline ridge region. They are predominantly forced by decadal fluctuations of surface wind stress associated with climate variability modes, while the impact of other processes is much smaller. The Somali coast and the western Bay of Bengal are two exceptional regions, where ocean internal (unforced) variability has large contribution. Between $28^{\circ}$ and $20^{\circ} \mathrm{S}$ in the subtropical south IO, surface heat flux and ocean internal variability are the major drivers of decadal sea level variability. Heat budget analysis for the upper $300 \mathrm{~m}$ of this region suggests that surface heat flux affects regional thermosteric sea level through both local surface heating and heat transport by ocean circulation. In the southwestern IO south of $30^{\circ} \mathrm{S}$, where stochastic winds are strong, stochastic wind forcing and its interaction with ocean internal variability generate pronounced decadal variations in sea level. The comprehensive investigation of decadal sea level variability over the IO from an oceanic perspective will contribute to decadal sea level prediction research, which has a high societal demand.
\end{abstract}

\section{Introduction}

\section{a. Indian Ocean sea level variability}

The global mean sea level has been rising at a rate of $\sim 3 \mathrm{~mm} \mathrm{yr}^{-1}$ during the past several decades as a result of thermal expansion and continental ice melt (Church et al. 2004, 2011, 2013; Bindoff et al. 2007; Willis et al. 2010; Hay et al. 2015). Regional sea level changes, however, deviate significantly from the global mean rate, with enhanced sea level rise in some regions and sea level fall in others (e.g., Unnikrishnan and Shankar 2007; Köhl and Stammer 2008; Stammer and Hüttemann 2008; Han et al. 2010; Merrifield 2011; Qiu and Chen 2012; Sallenger et al. 2012;

\footnotetext{
* Supplemental information related to this paper is available at the Journals Online website: http://dx.doi.org/10.1175/JCLI-D-15-0252.s1.

Corresponding author address: Yuanlong Li, Department of Atmospheric and Oceanic Sciences, University of Colorado, Campus Box 311, Boulder, CO 80309.

E-mail: yuanlong.li@colorado.edu
}

Stammer et al. 2013; Kenigson and Han 2014; Suzuki and Ishii 2015). Because of the profound socioeconomic and environmental impacts, regional sea level variability has been drawing increasing attention from researchers and policy makers. The Indian Ocean (IO), which is bounded by the African, Asian, and Australian continents (Fig. 1), has many low-lying islands and highly populated coastal zones. Sea level rise and land erosion affect the lives of millions of people. An improved understanding of decadal sea level variability over the IO in the changing climate will contribute to the decadal prediction effort and thus ultimately help society to plan and respond.

Sea level in the IO displays pronounced variability at seasonal, interannual, decadal, and multidecadal time scales. In this paper, decadal variability will refer broadly to the variations on time scales of a decade and longer $(\geq 10 \mathrm{yr})$. Existing studies suggest that interannual sea level variations, especially those within the tropical IO, are associated with the Indian Ocean dipole (IOD; e.g., Saji et al. 1999; Webster et al. 1999) and El Niño-Southern Oscillation (ENSO; e.g., Philander 1983). For instance, surface wind anomalies associated 
(a) Storm Activity $\left(\mathrm{H}_{300}\right)$

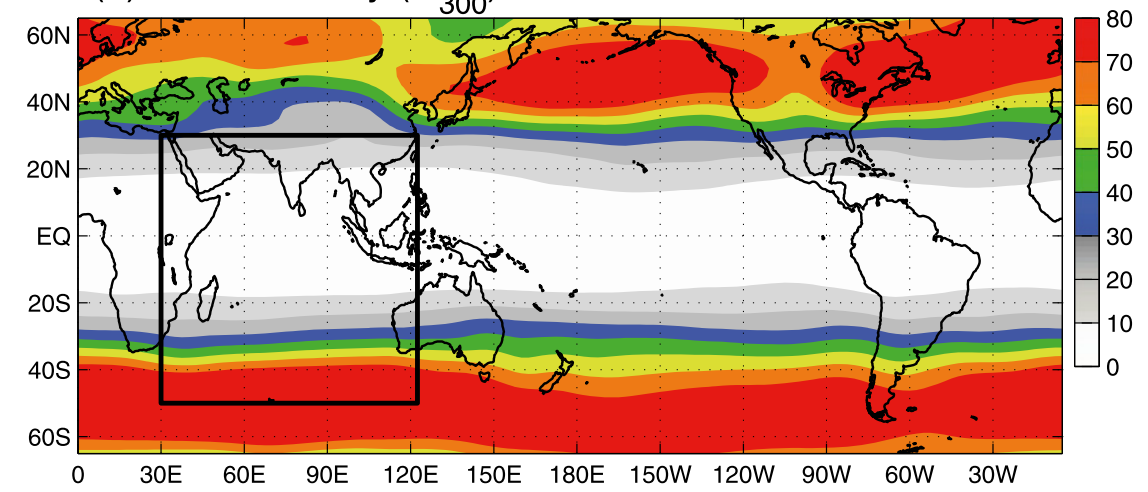

(b) Storm Activity $\left(\tau^{\mathrm{x}}\right)$

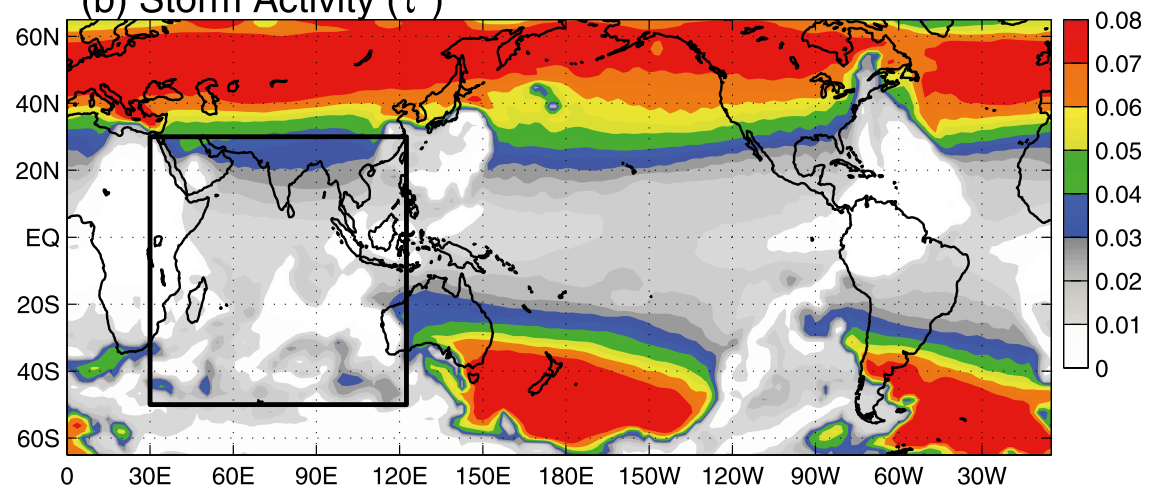

FIG. 1. Storm activity maps calculated as the 2-8-day STD of (a) 300-hPa geopotential height $H_{300}(\mathrm{~m})$ and (b) zonal wind stress $\tau^{x}\left(\mathrm{~N} \mathrm{~m}^{-2}\right)$ based on daily NCEP reanalysis data during 1948-2012. The black rectangle denotes the HYCOM model domain $\left(50^{\circ} \mathrm{S}-30^{\circ} \mathrm{N}, 30^{\circ}-122.5^{\circ} \mathrm{E}\right)$.

with the IOD cause sea level variations in the eastern equatorial IO, which subsequently propagate into the Bay of Bengal as coastal Kelvin waves (e.g., Clarke and Liu 1994; Han and Webster 2002; Rao et al. 2002, 2010) and into the western IO as Rossby waves (Webster et al. 1999). ENSO affects IO sea level through both atmospheric bridge and oceanic teleconnection. ENSOrelated strong wind stress curl anomalies south of the equator induce pronounced oceanic variations in the central-eastern IO (e.g., Xie et al. 2002; Yu et al. 2005). These variations propagate westward as Rossby waves, causing sea level and thermocline variations in the thermocline ridge region of the southwestern tropical IO (e.g., Perigaud and Delecluse 1993; Masumoto and Meyers 1998; Birol and Morrow 2001; Xie et al. 2002; Tozuka et al. 2010; Trenary and Han 2012). Furthermore, ENSO-induced ocean wave signals in the tropical Pacific can enter the IO through the Indonesian Archipelago, some of which propagate southward along the western Australian coast as coastal Kelvin waves and spread westward into the basin interior as Rossby waves (Potemra and Lukas 1999; Feng et al. 2003; Wijffels and Meyers 2004; Cai et al. 2005).
Compared with that of interannual variability, our knowledge of decadal time-scale sea level variability in the $\mathrm{IO}$ is rather limited because of the lack of long-term observations [see Han et al. (2014b) for a review]. Using tide gauge and satellite altimeter data, earlier studies detected decadal sea level variability along the coast of the Indian subcontinent (Shankar and Shetye 1999) and the west coast of Australia, and the latter was suggested to be forced remotely by Pacific winds via the Indonesian Throughflow (ITF) variability (Lee 2004; Feng et al. 2004, 2010, 2011). In the IO interior, decadal sea level variations are also observed, which exhibit distinct basin-scale patterns. Based on satellite altimeter data, Lee and McPhaden (2008) revealed a coherent decadal reversal of sea level trends in the tropical Indo-Pacific Ocean at the end of the twentieth century, with opposite trends from 1993-2000 to 2000-06. These variations were suggested to be associated with decadal changes of the Indo-Pacific trade winds and subtropical cells (e.g., Lee 2004; Lee and McPhaden 2008; Zhuang et al. 2013). Numerical modeling studies demonstrated that the basin-scale sea level patterns are primarily forced by winds over the IO basin, particularly for the strong 
variations in the southwestern IO thermocline ridge region (e.g., Nidheesh et al. 2013; Trenary and Han 2013). By contrast, sea level variations in the southeastern IO, especially those along the western Australian coast, were largely contributed by remote wind forcing from the Pacific. Trenary and Han (2013) suggested an increased contribution of ITF variability to the IO sea level variability since the early 1990 s, which is consistent with the intensification of decadal variability in trade winds and ocean circulation in the western tropical Pacific (e.g., Merrifield 2011; Luo et al. 2012; Qiu and Chen 2012; England et al. 2014; Han et al. 2014a) and the enhanced ITF and Leeuwin Current transports (Feng et al. 2011; Sprintall and Révelard 2014) in the same period.

Regarding the long-term trend, Unnikrishnan and Shankar (2007) detected sea level rising rates of 1.06$1.75 \mathrm{~mm} \mathrm{yr}^{-1}$ over the $1878-2004$ period from tide gauge records along the north IO coast. Using the reconstructed sea level data of Meyssignac et al. (2012), Palanisamy et al. (2014) estimated that the average rising rate for the IO sea level from 1950 through 2009 is $\sim 1.5 \mathrm{~mm} \mathrm{yr}^{-1}$, a value smaller than the global mean rate. Han et al. (2010) reported a distinct spatial pattern of IO sea level trend during 1961-2001, with sea level fall in the southwestern tropical IO and sea level rise elsewhere. The falling sea level in the southwestern tropical IO agrees with the observed subsurface cooling and thermocline shoaling since the 1960s in this region (e.g., Barnett et al. 2005; Han et al. 2006a; Alory et al. 2007; Trenary and Han 2008). Similar spatial patterns are derived from thermosteric (temperature related) sea level data based on in situ observation (Levitus et al. 2005), reconstructed sea level products (Hamlington et al. 2011), and numerical model simulations (e.g., Köhl and Stammer 2008; Timmermann et al. 2010; Schwarzkopf and Böning 2011; Nidheesh et al. 2013). Han et al. (2010) attributed the sea level trend mainly to surface wind change over the IO, while Schwarzkopf and Böning (2011) suggested significant contribution of Pacific wind forcing through the ITF. The discrepancy is likely related to the different wind products used in the two modeling studies.

\section{b. Unresolved issues}

Despite the recent progresses, our understanding of decadal sea level variability in the IO is far from complete. Surface wind forcing was shown to be important in causing decadal sea level variations, but the effects of decadal winds associated with climate modes versus stochastic wind forcing were not distinguished. The possible role of stochastic atmospheric forcing in causing IO decadal variability is unknown yet, whereas it has been identified as an important mechanism for low-frequency oceanic variability in the Pacific Ocean, the Atlantic Ocean, and the Southern Ocean (e.g., Frankignoul et al. 1997; Blanke et al. 1997; Sura and Penland 2002; Sura and Newman 2008; Sura et al. 2006; Flügel et al. 2004; Alexander et al. 2008; Chhak et al. 2009; Alexander 2010; Penland and Hartten 2014; Kondrashov and Berloff 2015).

Over the IO, a large portion of decadal wind variability is associated with climate modes, most notably the interdecadal Pacific oscillation (IPO; Power et al. 1999) and decadal modulations of interannual climate modes (e.g., ENSO and IOD). Another identified climate mode is the IO basin mode, which is the leading empirical orthogonal function (EOF) mode of the IO sea surface temperature (SST). This mode is primarily viewed as ENSO-induced variability at the interannual time scale (e.g., Klein et al. 1999). It was highly correlated with the IPO on the decadal time scale before the mid-1980s, but this correlation reversed sign afterward (Han et al. 2014a,b). Since decadal ENSO variability is highly correlated with the IPO, and to a lesser degree with the IO basin mode, in this paper we use an ENSO index to represent the decadal wind variations associated with IPO/ENSO and the IO basin mode (see section 2b).

By contrast, stochastic (random) forcing refers to the forcing by synoptic atmospheric disturbances, such as storms and tropical cyclones. Wind variability associated with these weather phenomena is "white" in spectral space, with no power peaks at preferred frequencies. Stochastic winds can affect decadal ocean variability through two mechanisms. The first (linear) mechanism is proposed by the pioneering work of Hasselmann (1976) and Frankignoul and Hasselmann (1977). They argued that like particles performing Brownian motion, the slow climate system exhibits random walk behavior, with the variability magnitude increasing with the square of its period. Even though stochastic wind variability has no preferred frequency (white power spectra), its oceanic response is "red" with enhanced power at low frequencies. As an application to wind-forced ocean variability, Han (2005) showed that in a linear ocean model without eastern boundary reflection, the equatorial IO current has a larger response to low-frequency wind forcing. The other (nonlinear) mechanism is rooted in the nonlinearity of the ocean system, through which high-frequency atmospheric forcing can modulate low-frequency oceanic variability. For example, atmospheric intraseasonal oscillations, such as the Madden-Julian oscillation (Madden and Julian 1971) and quasi-biweekly oscillations (Murakami and Frydrych 1974), can modulate the ENSO cycle (Kessler and Kleeman 2000) and IOD variability (Han 
et al. 2006b). In addition, Moore and Kleeman (1999) demonstrated that stochastic forcing can drive ENSO variability in a linearized ocean system. Midlatitude storm tracks account for a major portion of stochastic atmospheric variability. Calculated with $300-\mathrm{hPa}$ geopotential height $H_{300}$ (e.g., Nakamura et al. 2004; Lee et al. 2012), storm-track activity increases from the equator to midlatitudes, showing little zonal variation in the Southern Hemisphere (Fig. 1a). However, if calculated with surface wind stress (representing the forcing on the ocean), the activity is evidently lower in the south IO than in the other ocean basins (Fig. 1b). Whether and how the stochastic variability in the atmosphere can affect decadal sea level variability in the IO requires particular investigation.

While existing studies stressed the role of wind stress forcing in causing sea level variations, contributions from surface heat and freshwater fluxes have not been estimated. Since decadal sea level changes in the IO are mainly of thermosteric origin (e.g., Levitus et al. 2005; Köhl and Stammer 2008; Nidheesh et al. 2013), we expect that the surface heat flux, which can affect upperocean thermal structure, may exert a significant impact on sea level variability. Llovel and Lee (2015) also suggested a considerable contribution of a halosteric component to the recent sea level change in the southeastern IO, indicating a possible role played by freshwater flux in some areas of the IO.

Besides atmospheric forcing, decadal sea level variations can also arise from oceanic internal variability in regions where dynamical instabilities are active. In a nonlinear ocean system, even if forced by the climatological atmospheric fields, variability at various time scales can still arise. These variations are not forced externally by atmospheric variability but generated internally by instabilities of ocean circulation and stratification. Ocean internal variability can exist in various forms, such as mesoscale/submesoscale eddies, free waves, and large-scale fluctuations of circulation gyres. Trenary and Han (2013) have shown that ocean internal variability significantly contributes to decadal thermocline variations in the subtropical IO south of $20^{\circ} \mathrm{S}$. While most of the existing research focuses on the tropical IO basin and wind forcing effect, the subtropical south IO and the effect of ocean internal variability are rarely explored.

\section{c. Present research}

The present study aims to provide a comprehensive investigation for decadal sea level variations over the IO basin during the 1950-2012 period. This is pursued by performing a series of ocean general circulation model (OGCM) experiments to assess the relative contributions from wind forcing, heat and freshwater fluxes, stochastic winds, and ocean internal variability. Hopefully, this effort will improve our understanding of the regional decadal sea level variability in the $\mathrm{IO}$, which may contribute to the decadal prediction effort of the climate community. The rest of the paper is organized as follows. Section 2 outlines the OGCM configuration and experiment design. Section 3 describes the OGCMsimulated IO sea level variations from 1950 to 2012 and compares them with available satellite observations and reanalysis data. Section 4 explores causes for decadal sea level variations, underscoring the relative importance of different processes. Finally, section 5 summarizes the main findings of this study.

\section{Model and experiments}

\section{a. Model configuration}

The Hybrid Coordinate Ocean Model (HYCOM) combines isopycnal, sigma (terrain following), and $z$-level coordinates to optimize the representation of oceanic processes (Bleck 2002; Wallcraft et al. 2009). HYCOM has been successfully utilized to simulate sea level variations of the IO from intraseasonal to multidecadal time scales (e.g., Han et al. 2010; Trenary and Han 2012, 2013). In this study we configure HYCOM version 2.2 .18 to the $\mathrm{IO}$ basin $\left(50^{\circ} \mathrm{S}-30^{\circ} \mathrm{N}, 30^{\circ}-122.5^{\circ} \mathrm{E}\right.$; Fig. 1) with a horizontal resolution of $0.25^{\circ} \times 0.25^{\circ}(\mathrm{Li}$ et al. 2014). The model has 26 vertical layers, with layer thickness gradually enlarging from $3 \mathrm{~m}$ near the surface to about $500 \mathrm{~m}$ in the deep ocean. The diffusion and mixing parameters of the model are identical to those used in Li et al. (2013). Realistic marine bathymetry from the National Geophysical Data Center $2^{\prime}$ digital data is used as the model topography after a $1.5^{\circ} \times 1.5^{\circ}$ smoothing. The Red Sea and Persian Gulf are masked out. At sea surface, model salinity is relaxed to the monthly climatologic value of the World Ocean Atlas 2009 (WOA09) (Antonov et al. 2010; Locarnini et al. 2010) to suppress the long-term drift. No-slip conditions are applied along continental boundaries. At the western, eastern, and southern open-ocean boundaries $5^{\circ}$ sponge layers are applied to relax model temperature and salinity to WOA09 monthly climatology (see Fig. 1a in $\mathrm{Li}$ et al. 2015). The sponge layer on the eastern boundary considers the mean temperature and salinity properties of the ITF. This model configuration, however, excludes the remote forcing effect from the Pacific Ocean through ITF variability, which can affect the model simulations in the southeastern IO basin (e.g., Feng et al. 2004, 2010, 2011; Wijffels and Meyers 2004; Cai et al. 2005) and even the southwestern IO basin 
(Hirst and Godfrey 1993; Schwarzkopf and Böning 2011). Such influence will be discussed in section 3 .

The atmospheric surface forcing fields of HYCOM, including the daily wind speed, wind stress, net shortwave and longwave radiations, precipitation, and 2-m air temperature and humidity, are from the National Centers for Environmental Prediction-National Center for Atmospheric Research (NCEP-NCAR) reanalysis data (Kalnay et al. 1996), which have a $1.875^{\circ}$ horizontal resolution and are available since January 1948. The turbulent (latent plus sensible) heat fluxes are calculated with surface wind speed, air temperature, specific humidity, and the model SST, using the Coupled Ocean-Atmosphere Response Experiment version 3.0 (COARE 3.0) algorithm (Fairall et al. 2003; Kara et al. 2005). Zonal and meridional surface wind stress, $\tau^{x}$ and $\tau^{y}$, are calculated from the NCEP $10-\mathrm{m}$ wind speed $\left|V_{10}\right|$ using the standard bulk formula:

$$
\tau^{\mathrm{x}}=\rho_{a} c_{d}\left|V_{10}\right| u_{10} \quad \text { and } \quad \tau^{y}=\rho_{a} c_{d}\left|V_{10}\right| v_{10},
$$

where $\rho_{a}=1.175 \mathrm{~kg} \mathrm{~m}^{-3}$ is the air density, $c_{d}=0.0015$ is the drag coefficient, and $u_{10}$ and $v_{10}$ are the zonal and meridional components of 10-m winds. In our HYCOM experiments, oceanic dynamical processes and vertical entrainment are all driven by wind stress, while wind speed affects the ocean mainly through surface turbulent heat fluxes. We also use the satellite-derived monthly discharge records for the Ganga-Brahmaputra (Papa et al. 2010) and monthly river discharge data from Dai et al. (2009) in the Bay of Bengal. In our model configuration, both precipitation and river discharge are treated as virtual salt flux. Therefore, they affect sea level mainly through a halosteric effect (salinity change) rather than through mass change.

\section{b. Experiments}

The model is spun up from a state of rest for 30 years under monthly climatologic atmospheric forcing, using WOA09 annual climatology of temperature and salinity as the initial condition. Restarting from the already spun-up solution, HYCOM is integrated forward from January 1948 to December 2012 in four parallel experiments described below.

The main run (MR) is forced with daily NCEP forcing. It is the complete solution that contains both externally forced and internally generated processes in the IO. The MR is therefore used as the reference solution and compared with observations to evaluate the model performance.

The wind run (WND) is forced with daily NCEP wind stress, but all the other forcing fields, including wind speed, radiation, and precipitation, are fixed to monthly climatologic values of the 1948-2012 period. In the WND experiment, decadal sea level variations arise from only two sources: wind stress forcing and ocean internal variability. The difference solution (MR - WND) measures the effect of other atmospheric forcing (mainly heat and freshwater fluxes) on sea level.

The stochastic run (STCH) is forced by daily stochastic wind stress, with all the other forcing fields fixed to their monthly climatologic values. In STCH, decadal sea level variations arise from stochastic wind forcing and ocean internal variability. In this study, stochastic wind stress is constructed with NCEP daily wind using the method of Blanke et al. (1997) and Flügel et al. (2004). This method aims to remove the deterministic wind signals associated with SST variability and then construct the stochastic wind stress with the residual winds. The method involves three steps, and distributions of wind stress variance for each step are shown in Fig. S1 (see supplementary material). The first step is to remove the signal associated with ENSO (including the IPO variability and part of the IO basin mode variability) and IOD, the two most influential climate modes in the IO, from NCEP wind stress and SST data available from the Hadley Centre Sea Ice and SST dataset (HadISST) (Rayner et al. 2003). The ENSO- and IOD-related variations are obtained by performing a multiple linear regression onto the observed multivariate ENSO index (MEI) and dipole mode index (DMI). In the second step, we employ a singular value decomposition (SVD) technique to obtain the covariance of the residual wind stress and SST. The leading seven SVD modes are further removed from NCEP wind stress. The part of IO basin mode variability that is not induced by ENSO (or IPO) since the mid-1980s is also removed with the SVDs in this step. In the third step, we apply an EOF analysis to the residual wind stress and use the leading 30 EOF modes (explaining $66.8 \%$ of the total daily variance) to construct the stochastic wind stress $\tau_{*}$ :

$$
\left[\tau_{*}^{x}(x, y, t), \tau_{*}^{y}(x, y, t)\right]=\sum_{n=1}^{30}\left[\tau_{n}^{x}(x, y), \tau_{n}^{y}(x, y)\right] \cdot R_{n}(t) \cdot A_{n} .
$$

In the above, $\tau_{n}^{x}(x, y)$ and $\tau_{n}^{y}(x, y), n=1, \ldots, 30$ are the $n$th EOF mode of zonal and meridional wind stress, $R_{n}(t)$ is a random daily time coefficient varying between -1 and 1 , and $A_{n}$ is a scaling factor that weights the individual EOF mode according to its explained percentage of variance. The constructed stochastic wind spectrum is white, with no red spectral signals at preferred frequencies (Fig. S2 in the supplementary material). As pointed out by one of the reviewers, using the 1948-2012 NCEP 


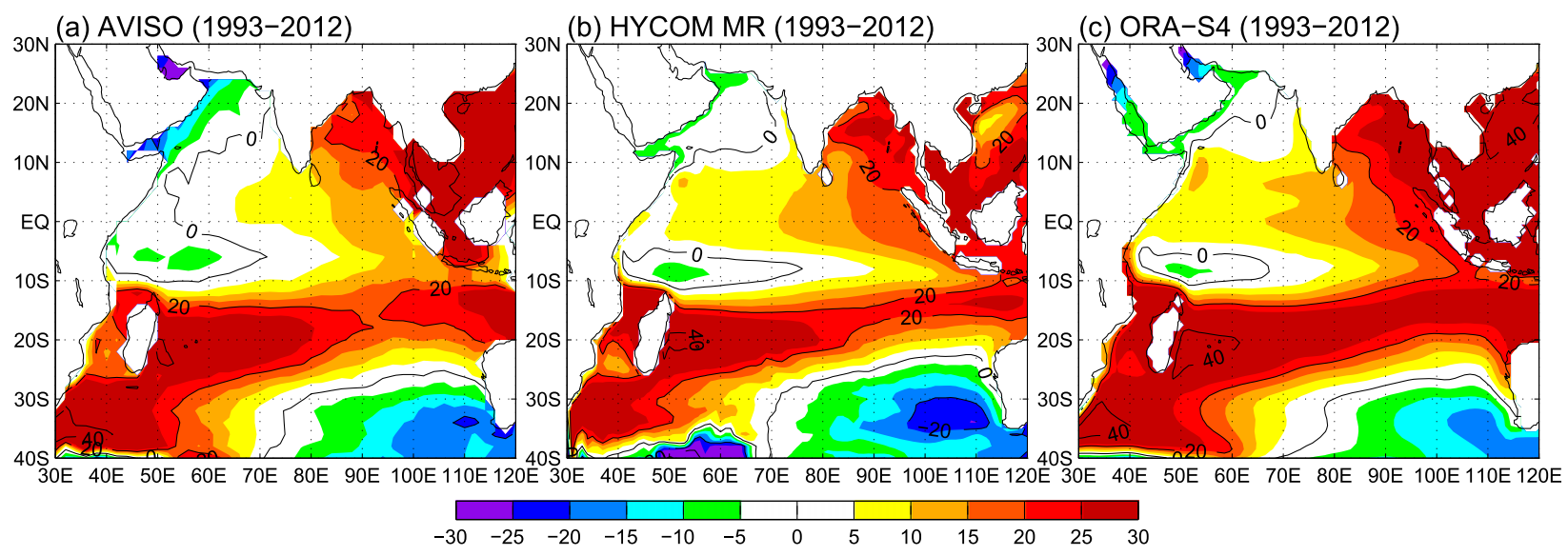

FIG. 2. Annual mean sea level maps (cm) during 1993-2012 from (a) AVISO satellite data, (b) HYCOM MR output, and (c) ECMWF ORA-S4 data. The IO basin mean sea level value has been removed before plotting.

data to construct stochastic forcing may be problematic because there was little observation capable of resolving midlatitude storms until the advent of weather satellites in the late 1970s. The NCEP data prior to the late 1970s may corrupt the constructed stochastic winds. To evaluate such impact, we compare the wind stress variance of two periods: 1948-79 and 1980-2012. Figure S3 in the supplementary material shows that between the two periods, variance distributions are basically identical to each other, and their total variances are quite close (the difference is not significant according to a two-tailed $F$ test). Therefore, the quality of the early-part NCEP data is not likely a severe problem for the constructed stochastic wind stress.

Finally, the climatologic run (CLM) is forced with only monthly climatologic forcing fields. In this solution, decadal sea level variations arise solely from ocean internal variability. In CLM, the average net surface heat flux for the entire model domain is $2.94 \mathrm{~W} \mathrm{~m}^{-2}$ downward for the 1948-2012 period. This net heat gain by the IO may arise from the global warming effect (contained in the longwave radiation) and errors in the forcing and modeled SST fields. As a result, there is a slow mean sea level rise in CLM due to thermal expansion. To focus on regional decadal sea level variability, we remove the long-term sea level trend of CLM (Fig. S4 in the supplementary material) from each of the four HYCOM experiments.

Model outputs from the four experiments are stored in monthly resolution, and the results of 1948 and 1949 are discarded to reduce the transient effect caused by switching forcing fields from the spinup run. The 63-yr data from 1950 through 2012 are used for our analysis. To highlight decadal variations ( $\geq 10 \mathrm{yr}$ ), we mainly analyze the 8-yr low-pass-filtered anomaly data, from which the monthly climatology is subtracted before applying a Hanning-window low-pass filter. Four years of data are discarded from the beginning and the end of the low-passed anomaly data to remove the filter's endpoint effect.

\section{Simulated sea level variations}

To evaluate HYCOM's performance in simulating the IO sea level, we compare the HYCOM MR solution with the multisatellite merged altimeter sea surface height (hereafter referred to as sea level) data and sea level anomaly (SLA) products since October 1992 distributed by the Archiving, Validation, and Interpretation of Satellite Oceanographic Data (AVISO) (Le Traon et al. 1998; Ducet et al. 2000). The AVISO sea level value is the sum of SLA and mean dynamic topography based on GRACE data, altimetry measurements, and in situ observations (Rio et al. 2011). For a longer-period reference, we also utilize the $1^{\circ} \times 1^{\circ}$ ocean reanalysis data of the European Centre for MediumRange Weather Forecasts (ECMWF) Ocean Reanalysis System 4 (ORA-S4) since January 1958 (Balmaseda et al. 2013). The ocean model of ORA-S4 uses the ECMWF atmospheric reanalysis data (ERA-40 and ERA-Interim) as the forcing fields and assimilates AVISO altimeter sea level product and satellite/in situ ocean temperature/salinity measurements. The annual mean SSH maps for the 1993-2012 period from AVISO, HYCOM MR, and ORA-S4 are displayed in Fig. 2. The three datasets show general agreement in large-scale structure, with high sea level in the eastern tropical IO, the zonal band of $25^{\circ}-15^{\circ} \mathrm{S}$, and southwestern subtropical IO. Compared to AVISO and ORA-S4 data, the modeled SSH has an unrealistic low-value area around $40^{\circ}-35^{\circ} \mathrm{S}, 40^{\circ}-70^{\circ} \mathrm{E}$, which may be partly caused by the errors in the forcing fields such as radiation (not shown) and strong ocean internal variability. In addition, the western boundary of the model domain is at 
(a) AVISO (1993-2000)

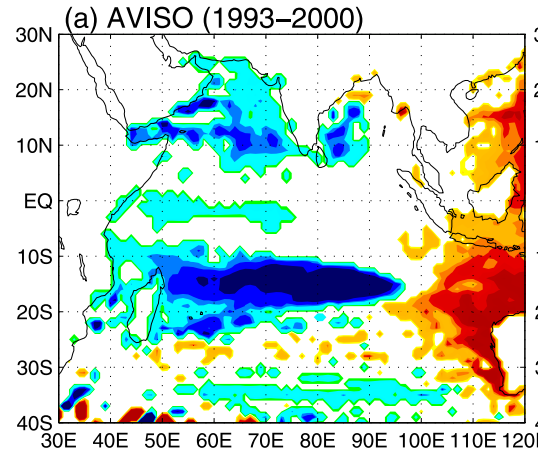

(b) HYCOM MR (1993-2000)

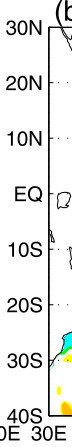

(b) HYCOM MR (1993-2000)

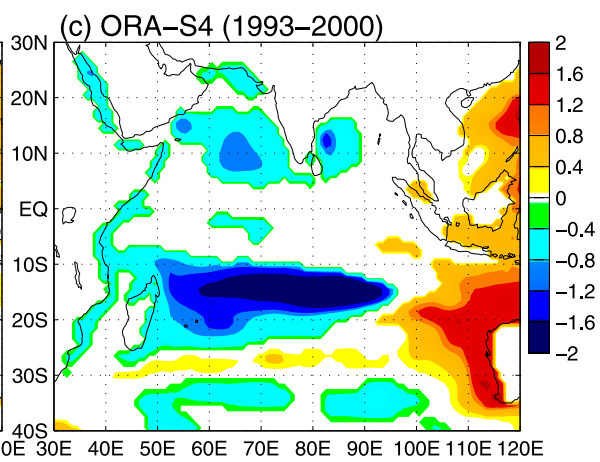

${ }_{30 N}$ (d) AVISO (2001-2008)

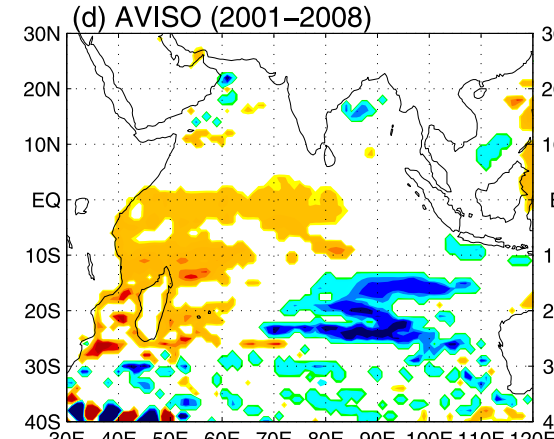

(e) HYCOM MR (2001-2008)

(f) ORA-S4 (2001-2008)

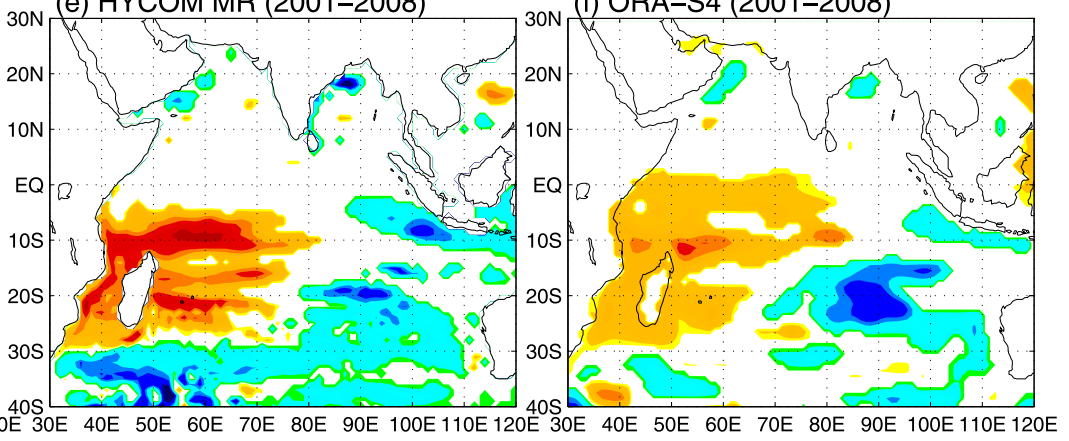

FIG. 3. Linear sea level trend ( $\mathrm{cm} \mathrm{yr}^{-1}$ ) for the 1993-2000 period from (a) AVISO satellite data, (b) HYCOM MR output, and (c) ORA-S4. (d)-(f) As in (a)-(c), but for the 2001-08 period. Trend values below $90 \%$ statistical significance are plotted white. The IO basin mean sea level time series is removed before calculating the trends.

$30^{\circ} \mathrm{E}$. The water exchange between the IO and the Atlantic Ocean through the Agulhas leakage around the southern tip of Africa (e.g., Gordon 1985; Lutjeharms and Van Ballegooyen 1988; Beal et al. 2011) is not properly represented, leading to unrealistic simulation of the ocean state in the southwestern corner of the model domain. Therefore, our analysis will be mainly confined in the IO basin north of $35^{\circ} \mathrm{S}$. The $35^{\circ}-30^{\circ} \mathrm{S}$ region will also be interpreted with caution.

During the satellite altimeter period, a decadal sea level trend reversal was observed in the tropical IndoPacific Ocean (Lee and McPhaden 2008). Figure 3 compares its representations in different datasets. To exclude the global mean sea level rise signal induced by glacial retreat and highlight regional sea level change pattern over the IO, here we have removed the IO basin mean sea level time series. During 1993-2000, the observed sea level exhibits a strong negative trend $\left(>1.5 \mathrm{~cm} \mathrm{yr}^{-1}\right)$ in the tropical south IO and weaker ones in the Arabian Sea, the western Bay of Bengal, and the subtropical south IO between $40^{\circ}$ and $30^{\circ} \mathrm{S}$ (Fig. 3a). Most of these signals are successfully captured by HYCOM (Fig. 3b). HYCOM has also reproduced the sea level rise in the subtropical area between $30^{\circ}$ and $25^{\circ} \mathrm{S}$ and the eastern IO. However, the sea level rise signals in the southeastern IO are greatly underestimated in HYCOM MR. This result is expected because variations in this region are strongly influenced by remote wind forcing of the Pacific Ocean (e.g., Feng et al. 2011; Nidheesh et al. 2013; Trenary and Han 2013), which is not included in our model. In addition, HYCOM presents sea level rise signals in the central-to-eastern equatorial IO, which do not exist in AVISO and ORA-S4 data. During 2001-08, there is a rapid sea level rise in the western tropical IO and a weak drop in the southeastern tropical IO and subtropical south IO (Figs. 3d,f). A similar pattern appears in the HYCOM result (Fig. 3e), except with quantitative discrepancies.

Standard deviation (STD) of the 8-yr low-pass-filtered SLA quantifies the intensity of decadal sea level variability. In the STD map based on ORA-S4 data (Fig. 4a), a coherent zonal band of large values $(>2.5 \mathrm{~cm})$ stands out in the tropical south IO between $15^{\circ}$ and $5^{\circ} \mathrm{S}$. Another tongue of large STDs extends southeastward from Madagascar to the central IO basin between $28^{\circ}$ and $18^{\circ} \mathrm{S}$. These two high-variability zones are faithfully reproduced by HYCOM (Fig. 4b), albeit with larger amplitudes. Similar to Fig. 3, HYCOM underrepresents the variations in the southeastern IO as a result of the exclusion of the Pacific Ocean wind forcing. On the other hand, HYCOM-simulated sea level variability is evidently stronger than ORA-S4 data in several areas, such as the southwestern corner of the IO, the western Bay of Bengal, and the Great Whirl area off the 
(a) ORA-S4

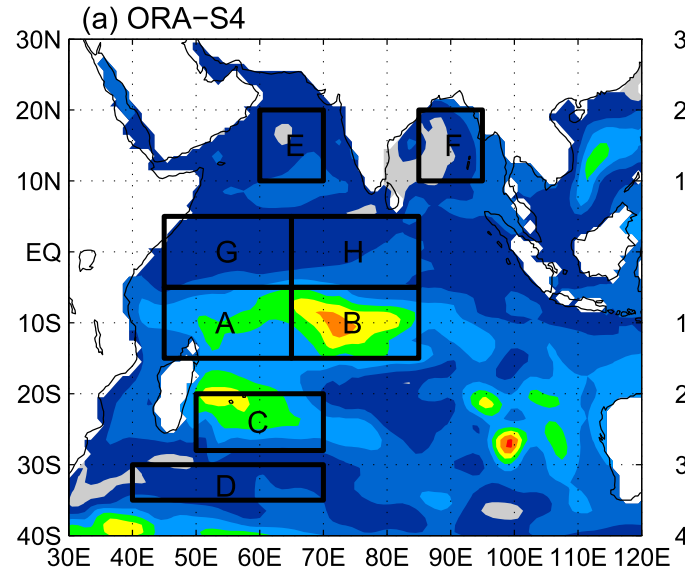

(b) MR

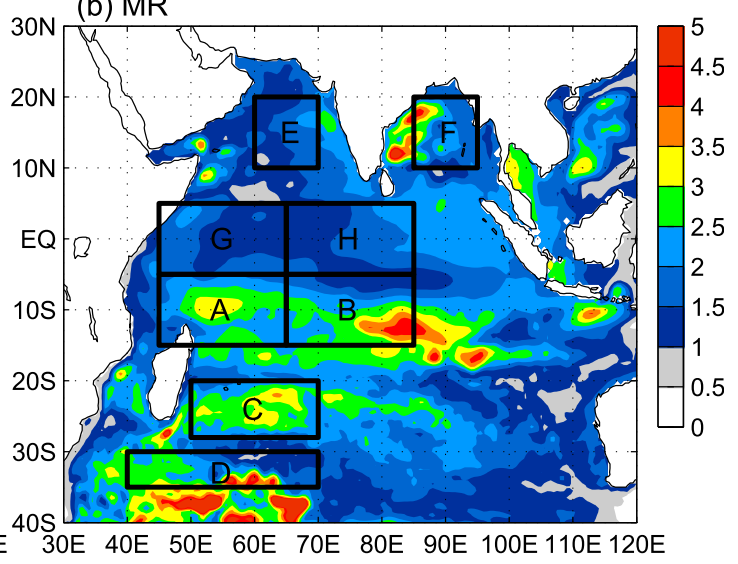

FIG. 4. STD of 8-yr low-pass-filtered SLA (cm) during 1962-2008 based on (a) ORA-S4 data and (b) HYCOM MR. Black rectangles denote the areas of regions $\mathrm{A}-\mathrm{H}$.

Somali coast. A mutual feature of the three areas is the high mesoscale eddy activity due to ocean internal variability, which has been reported by many observational studies (e.g., Tsai et al. 1992; van Ballegooyen et al. 1994; Biastoch and Krauss 1999; Wirth et al. 2002; Jia et al. 2011; Chen et al. 2012). The ORA-S4 has $1^{\circ} \times 1^{\circ}$ horizontal resolution in the extratopics and refined meridional resolution in the tropics, with a minimum value of $0.3^{\circ}$ near the equator (Balmaseda et al. 2013). Strong ocean internal variability and its rectification on decadal ocean variability are not sufficiently resolved in ORA-S4.

To facilitate further comparison and analysis, we define eight regions (i.e., regions A-H in Fig. 4) covering the large-amplitude sea level changes over the westernto-central IO. Respectively, regions A $\left(15^{\circ}-5^{\circ} \mathrm{S}, 45^{\circ}-\right.$ $\left.65^{\circ} \mathrm{E}\right)$ and $\mathrm{B}\left(15^{\circ}-5^{\circ} \mathrm{S}, 65^{\circ}-85^{\circ} \mathrm{E}\right)$ represent the western and central tropical south $\mathrm{IO}$; regions $\mathrm{C}\left(28^{\circ}-20^{\circ} \mathrm{S}, 50^{\circ}-\right.$ $\left.70^{\circ} \mathrm{E}\right)$ and $\mathrm{D}\left(35^{\circ}-30^{\circ} \mathrm{S}, 40^{\circ}-70^{\circ} \mathrm{E}\right)$ represent the subtropical south IO; regions $\mathrm{E}$ and $\mathrm{F}$ represent the Arabian Sea $\left(10^{\circ}-20^{\circ} \mathrm{N}, 60^{\circ}-70^{\circ} \mathrm{E}\right)$ and the Bay of Bengal $\left(10^{\circ}-\right.$ $\left.20^{\circ} \mathrm{N}, 85^{\circ}-95^{\circ} \mathrm{E}\right)$, covering the tropical north IO; and regions $\mathrm{G}\left(5^{\circ} \mathrm{S}-5^{\circ} \mathrm{N}, 45^{\circ}-65^{\circ} \mathrm{E}\right)$ and $\mathrm{H}\left(5^{\circ} \mathrm{S}-5^{\circ} \mathrm{N}, 65^{\circ}-\right.$ $85^{\circ} \mathrm{E}$ ) represent the western and central equatorial IO. After removing the seasonal cycle, the monthly SLAs averaged in these boxes exhibit fluctuations from interannual to decadal time scales (Fig. 5). The correlation between HYCOM MR and AVISO data is highest in region $\mathrm{B}(r=0.80)$ and around 0.70 in regions $\mathrm{A}, \mathrm{F}$, and $\mathrm{H}$. The correlation drops to 0.63 in regions $\mathrm{E}$ and $\mathrm{G}$ and further decreases to 0.56 in region $\mathrm{C}$. The simulated sea level shows little consistency with AVISO data in region D. The correlation with ORA-S4 data exhibits similar spatial variation. To a large degree, the HYCOM-data correlations depend on the dominating mechanism for sea level variability. In the tropical IO (north of $20^{\circ} \mathrm{S}$ ) interior, sea level variability is mainly driven by winds associated with climate modes. In this situation, HYCOM can well reproduce the observed sea level variations. In subtropical regions (south of $20^{\circ} \mathrm{S}$ ) where ocean internal variability is strong, such as regions $\mathrm{C}$ and D (e.g., van Ballegooyen et al. 1994; Biastoch and Krauss 1999; Trenary and Han 2013), a large portion of sea level variability cannot be reproduced by the model in the right phase. We will show in section 4 that sea level variations in region $\mathrm{D}$ are dominated by ocean internal variability and stochastic wind forcing effects, both of which are not predictable for HYCOM. In region D, even the ORA-S4 data show some discrepancies with the AVISO record, although AVISO sea level data have already been assimilated. If the seasonal cycle is retained, all the correlations are significantly upgraded (Fig. S5 in the supplementary material). This is because seasonal sea level variations are controlled by deterministic forcing processes, such as radiation and monsoonal winds, which can be well reproduced by HYCOM.

\section{Causes of decadal sea level variations}

\section{a. Relative importance of different processes}

Albeit with some discrepancies from observational data, HYCOM is able to reasonably reproduce most of the decadal sea level variations in the western-to-central IO; this is the subject of the following analysis. Effects of different processes can be assessed with HYCOM experiments. For instance, the decadal sea level STD (calculated from 8-yr low-passed SLA) of the WND run, denoted by STD(WND), quantifies the combined effect of wind stress forcing and ocean internal variability on 

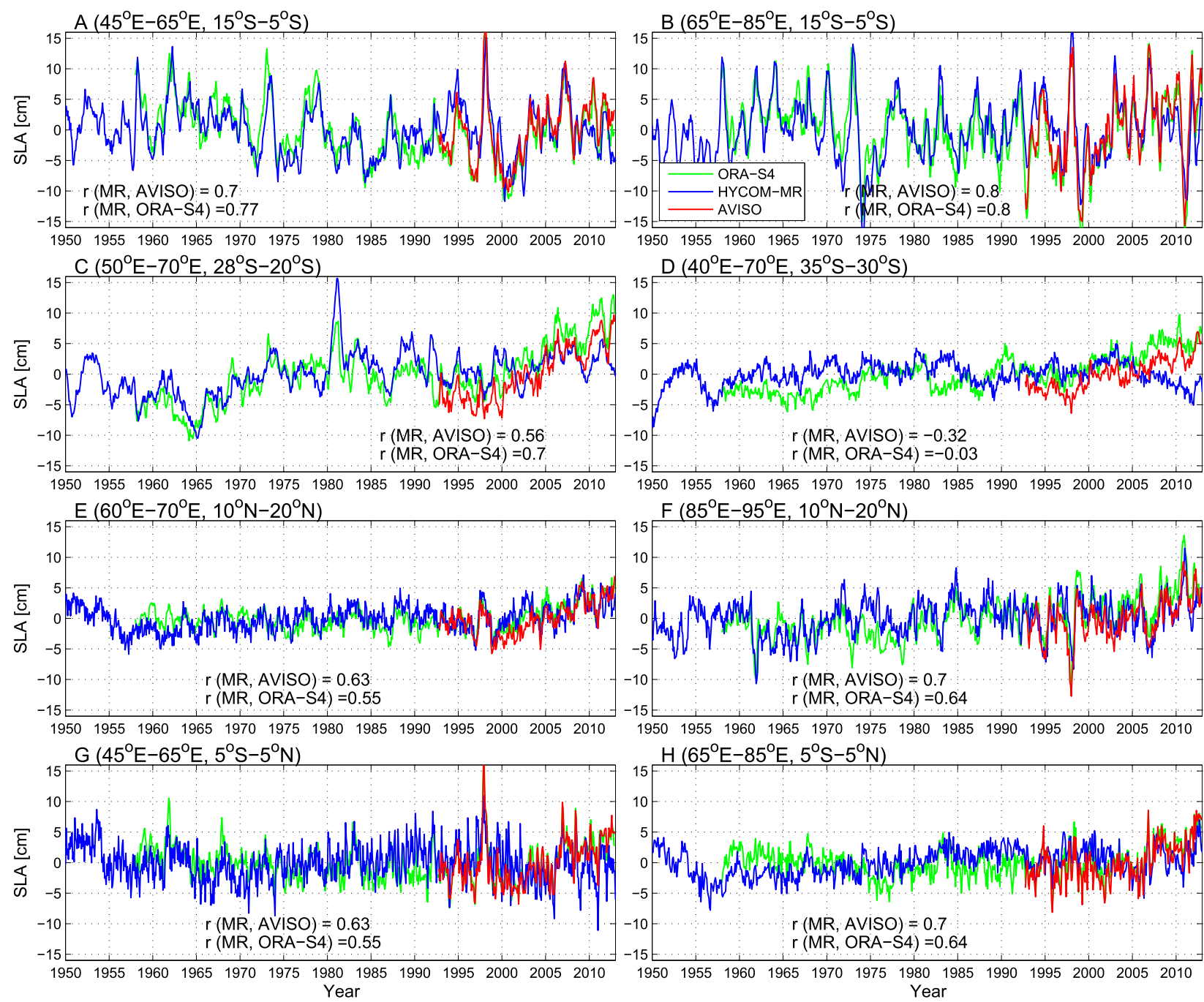

FIG. 5. Monthly SLA time series from AVISO satellite data (red), HYCOM MR (blue), and ORA-S4 data (green) averaged over regions A-H. The mean seasonal cycle has been removed.

decadal sea level variability (Fig. 6a). Its spatial pattern and typical magnitudes are quite close to the total variability in the MR (Fig. 4b). On the other hand, sea level variability in the CLM run, denoted by STD(CLM), contains only the effect of ocean internal variability. Therefore, the solution difference STD(WND) STD(CLM) is a measure of the wind stress effect on decadal sea level variability, even though the internal variability effect cannot be completely removed, owing to its unpredictable nature in each solution. Similar to Figs. $4 \mathrm{~b}$ and $6 \mathrm{a}$, the wind stress effect (Fig. 6b) exhibits a zonal band of large STDs $(>2.0 \mathrm{~cm})$ in the thermocline ridge region of the tropical south IO and has strong influence in most areas of the tropical basin. Within the tropical band, there are two exceptional areas where the wind stress effect is significantly weaker than the total variability in MR-namely, the Somali coast and the western Bay of Bengal. The wind stress forcing effect is evidently attenuated south of $20^{\circ} \mathrm{S}$, although it still has some influence near $30^{\circ} \mathrm{S}$ and in the southwestern subtropical area. Ocean internal variability, quantified by STD(CLM), is generally weak in the tropical IO north of $10^{\circ} \mathrm{S}$ (Fig. 6c), except for the Somali coast and the western Bay of Bengal. Large effects mainly exist in the subtropical south IO, with the maximum effect in the southwestern subtropical area $(>2 \mathrm{~cm})$.

The effect of heat and freshwater fluxes can be measured by the difference between MR and WND [i.e., STD(MR) - STD(WND)] (Fig. 6d). This effect shows large magnitudes $(>1.0 \mathrm{~cm})$ in the subtropical south IO, accounting for more than $40 \%$ of the total variability in the MR (1.0-1.5 cm in Fig. $6 \mathrm{~d}$ versus $2.0-2.5 \mathrm{~cm}$ in Fig. 4b). Another noticeable region is around the Indian subcontinent, where weaker and noisier signatures with 
(a) STD (WND)

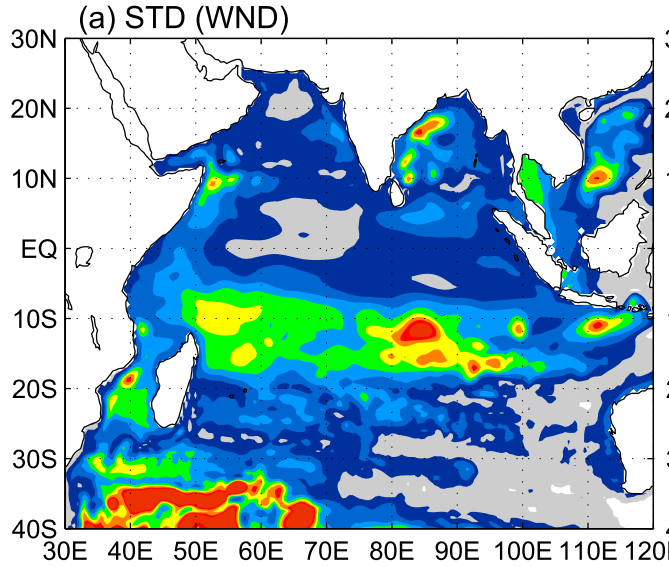

(c) STD (CLM)

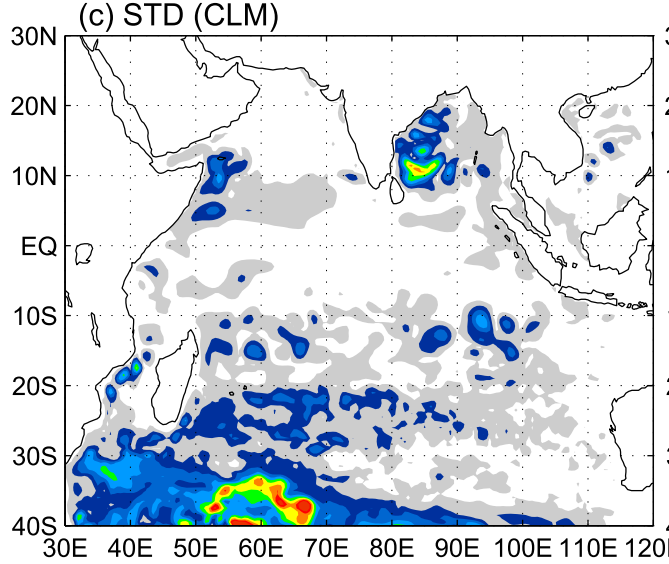

30E 4OE 50E GOE 70E 80E 9OE 100E 110E 120E 30E

(e) STD (STCH)
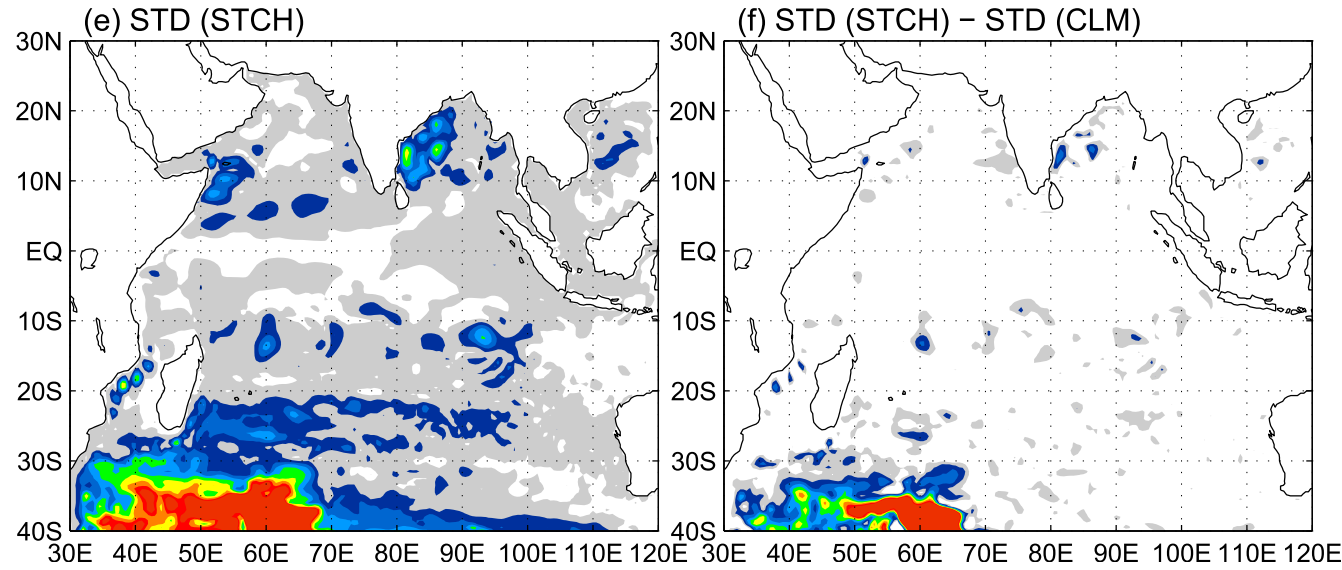

(b) STD (WND) - STD (CLM)

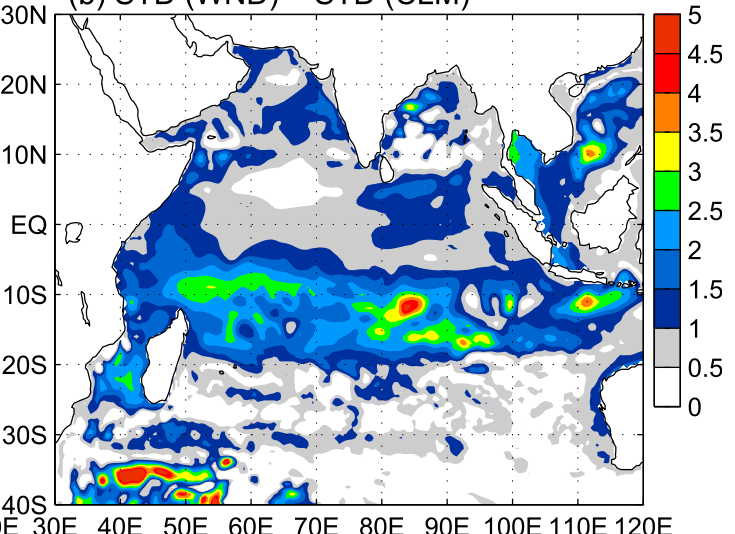

(d) STD (MR) - STD (WND)

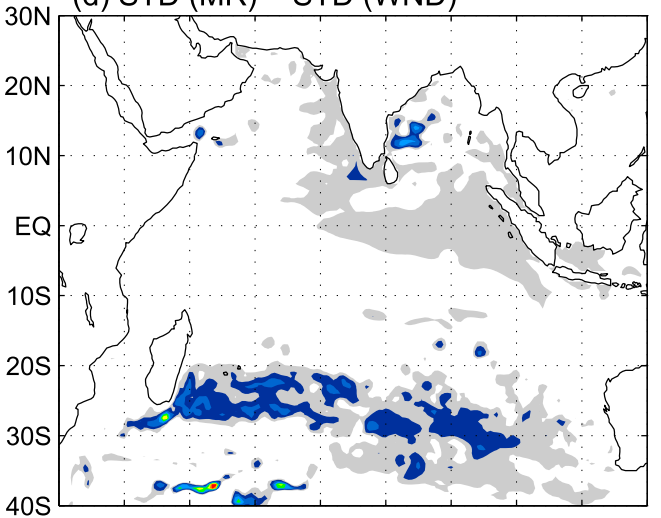

OOE 40E 50E 60E 70E 80E 90E 100E 110E 120E

(f) STD (STCH) - STD (CLM)

FIG. 6. (a) Decadal SLA STD (cm) of STD(WND) and (b) its difference from the CLM experiment STD(WND) STD(CLM). (c) Decadal SLA STD of STD(CLM). (d) Decadal SLA STD difference between MR and WND STD(MR) STD(WND). (e) Decadal SLA STD STD(STCH) and (f) its difference from the CLM experiment STD(STCH) - STD(CLM). Decadal STDs are computed with 8-yr low-passed SLA during 1954-2008.

STDs $>0.5 \mathrm{~cm}$ are seen. Stochastic wind forcing effect can be quantified by subtracting ocean internal variability effect from the STD of the STCH run (Fig. 6e). The difference STD(STCH) - STD(CLM) (Fig. 6f) is large in the southwestern subtropical region, with greater magnitudes than any other effect. This large-effect area also partly overlies the region of strong ocean internal variability effect. For the rest of the IO basin, the stochastic forcing effect is weak and noisy. These noisy signals may result partly from the ocean internal variability, which may not have exactly the same magnitudes in STCH and CLM. The striking contrast between Fig. $6 \mathrm{~b}$ and Fig. $6 \mathrm{f}$ 

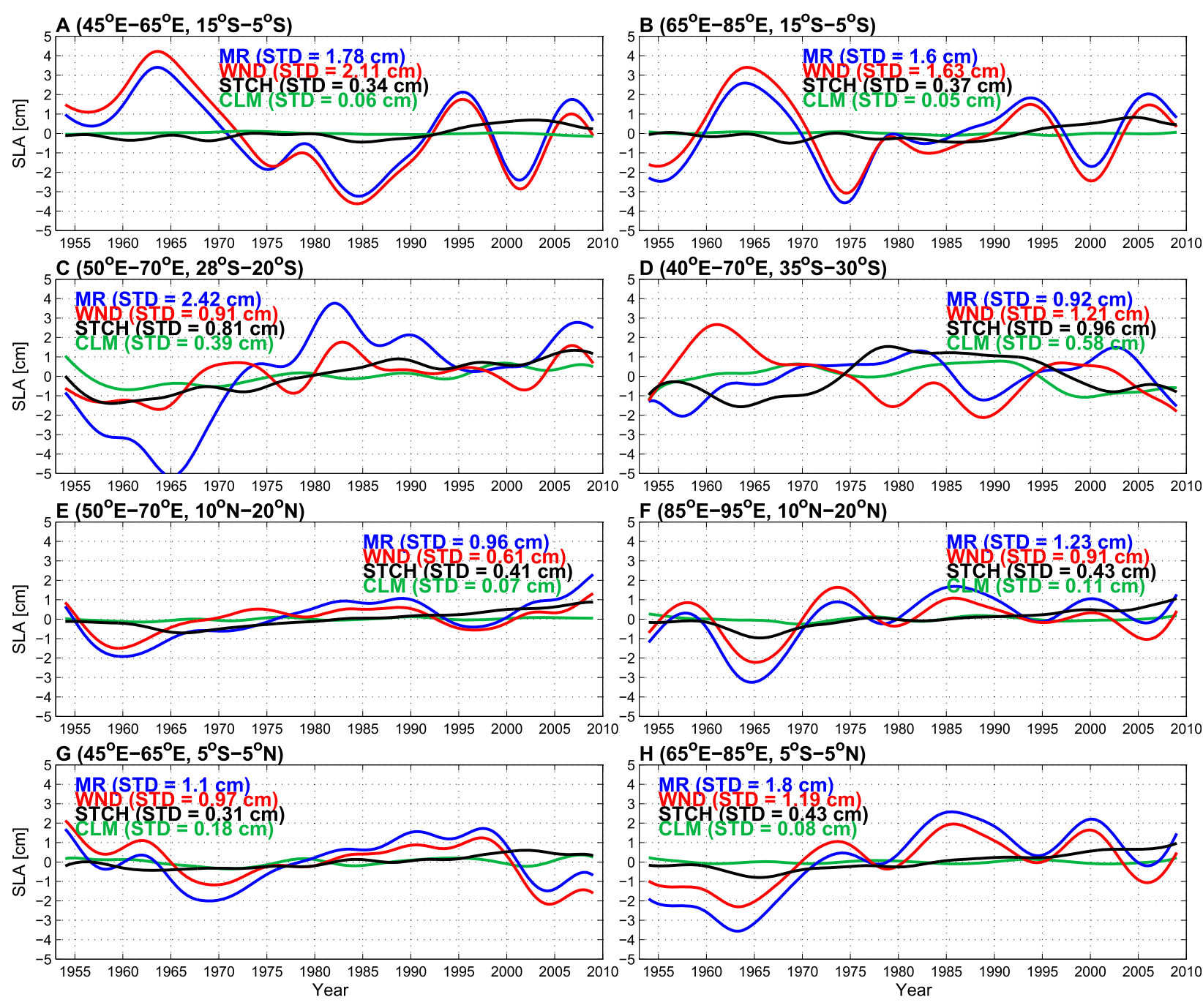

FIG. 7. The 8-yr low-pass-filtered SLA from MR (blue), WND (red), STCH (black), and CLM (green) averaged over regions A-H.

indicates a large spatial variation in the wind forcing mechanism. While decadal wind variability in the tropical IO is dominated by climate modes, stochastic winds play an important role in the subtropical IO, similar to the situation of other midlatitude ocean basins (e.g., Frankignoul et al. 1997; Chhak et al. 2009). Remember that, as a result of their interactions, the effects of different processes do not linearly add up to the total variability.

The above analysis shows large spatial variation in the main cause of decadal sea level variability, pointing to the need for separately investigating different regions. Before proceeding to that, we need to examine the significance of the spatial distributions shown in Figs. 4 and 6 . This is done by testing the sensitivity of these spatial patterns to data sampling. We recalculate the STDs of ORA-S4, MR, WND, STCH, and CLM by selectively omitting one decade of data. The STD maps without the data of the 1960s, 1970s, 1980s, and 1990s are shown in Fig. S6 of the supplementary material, which turn out to be consistent with those calculated with the full-length data in Figs. 4 and 6, although some detailed quantitative differences can be seen. This comparison suggests that the spatial patterns of decadal sea level variability and its mechanisms are robust and representative for the 1954-2008 period.

Figure 7 displays the 8-yr low-passed SLA time series averaged for each region of $\mathrm{A}-\mathrm{H}$ from different experiments. The area-mean computation averages out the small-scale structures and thus highlights the large-scale variations. The situations in the tropical regions $(\mathrm{A}, \mathrm{B}$, and $\mathrm{E}-\mathrm{H}$ ) are quite similar, with the WND SLA (red) resembling the MR SLA (blue). In regions A and B (tropical south IO), SLA of the WND run has a larger amplitude than that of the MR. In region A, the WNDversus-MR difference (2.11 versus $1.78 \mathrm{~cm}$ ) is in fact 
primarily contained in the long-term trend. If we remove the trend, the difference becomes much smaller (1.86 versus $1.71 \mathrm{~cm}$ ). In the tropical south $\mathrm{IO}$, wind stress drives most of the total variability, and the overall effect of other processes is to slightly dampen the wind-driven variability. In the equatorial and the tropical north IO (regions E-H), STD of the WND SLA is about $60 \%-$ $90 \%$ of the total variability in the MR. The differences between MR and WND indicate that heat and freshwater fluxes also contribute in some years. Sea level variability caused by stochastic wind forcing (black curve) equals $\sim 20 \%-30 \%$ of the total variability (although not consistent in phase), whereas the effect of ocean internal variability is much smaller (green curve). The weak influence from internal variability shown in Fig. 7 seems to contradict its large amplitudes shown in Fig. 6c. This is because sea level variations resulting from ocean internal variability usually possess small spatial structures (e.g., Qiu et al. 2015; Sérazin et al. 2015), which have been averaged out in Fig. 7. By contrast, stochastic wind forcing in the tropical IO is associated with large-scale synoptic-to-intraseasonal atmospheric variability, such as tropical cyclones (e.g., Fritz et al. 2009) and intraseasonal oscillations (e.g., Madden and Julian 1971; Murakami and Frydrych 1974), which can induce large-scale sea level variability.

Compared with the tropical IO, the subtropical IO is less explored. Sea level variability in this area will be the focus of the following analysis. In region $\mathrm{C}\left(28^{\circ}-20^{\circ} \mathrm{S}\right)$, SLA of the MR experienced strong decadal fluctuations, with a rapid fall from the mid-1950s to 1965 , a continuous rise from 1965 to 1982, a fall from 1982 to the mid1990s, and a rebound in the 2000s. Comparisons with AVISO and ORA-S4 data demonstrate that these decadal variations are realistic (Fig. 5). The wind stress effect is generally in phase with MR and explains part of the MR variability, but its amplitude is only $37.6 \%$ of the total variability $(0.91$ versus $2.42 \mathrm{~cm}$ in STD). The stochastic wind forcing effect and ocean internal variability both have considerable amplitudes $(0.81$ and $0.39 \mathrm{~cm}$ in STD), accounting for $33.5 \%$ and $16.1 \%$ of the total MR STD. They primarily contribute to the upward trend in the MR. The large difference between the MR and WND suggests the important roles played by surface heat and freshwater fluxes, as indicated by Fig. 6b. These effects will be discussed in detail in section $4 \mathrm{~b}$. The MR SLA in region D $\left(35^{\circ}-30^{\circ} \mathrm{S}\right)$ also exhibits strong decadal fluctuations. In this region, effects of different processes have comparable magnitudes. SLA of WND has a larger magnitude than MR (1.21 versus $0.92 \mathrm{~cm}$ in STD). Wind stress forcing is likely important in causing the decadal fluctuations after 1985. The stochastic wind forcing and ocean internal variability effects also have large magnitudes. The complicated mechanisms in this region will be discussed in section $4 \mathrm{c}$.

\section{b. Region $C$ and heat flux forcing}

The large difference between MR and WND in region $\mathrm{C}$ indicates the impact from other atmospheric fields. A possible candidate is surface heat flux forcing, which can induce sea level variability through the thermosteric effect. To test this hypothesis, we compare the upper-ocean temperature fields from MR and WND. Figure 8 displays the decadal evolutions of potential temperature $\Theta$ profiles averaged for region $\mathrm{C}$ and also region $\mathrm{A}$ for comparison. In region A (southwestern tropical IO) where wind stress forcing dominates, $\Theta$ evolution of the WND run bears remarkable resemblance to that of the MR (Figs. 8a,b). By contrast, there are apparent differences between MR and WND in region C (Figs. 8c,d). Large $\Theta$ anomalies are seen in the upper $300 \mathrm{~m}$ of the MR solution with amplitudes larger than $0.5^{\circ} \mathrm{C}$ (Fig. 8c), which are quite consistent with the concurrent sea level changes. Specifically, the cooling from the mid-1950s to 1965 corresponds to a sea level fall for this period (blue curve for region $\mathrm{C}$ in Fig. 7), the weakened cooling from 1965 to the 1970s and warming afterward until about 1982 correspond to a sea level rise, the weakened warming from about 1982 until 2000 coincides with a sea level fall, and enhanced warming since 2000 agrees with a sea level rise. In comparison, thermal variability in the WND run is much weaker (Fig. 8d), but it is in phase with that of the MR (Fig. 8c). This result agrees with our earlier finding that wind forcing of climate modes can explain part of the sea level variability in this area. Another interesting feature is the discernible downward spreading of $\Theta$ anomalies in Fig. 8c, which is absent in Figs. $8 \mathrm{a}, 8 \mathrm{~b}$, and $8 \mathrm{~d}$. This feature implies a possibility that in region $\mathrm{C}$, most of the $\Theta$ anomalies are generated at the sea surface by heat fluxes and gradually penetrate downward. In both region $\mathrm{A}$ and the WND experiment (Figs. 8a,b,d), large $\Theta$ anomalies occur in the thermocline. In Fig. $8 \mathrm{c}, \Theta$ anomalies also have large amplitudes in the thermocline layer (e.g., 50-300 m). This likely indicates that the $\Theta$ anomalies produced by the heat flux are further strengthened by wind-driven $\Theta$ anomalies, given that the wind stress effect is basically in phase with MR variability in region $\mathrm{C}$.

To quantify the heat flux effect, we further carry out the following analysis. The total SLA $\eta^{\prime}$ of MR - WND (Fig. 9a) can be decomposed into the thermosteric $\eta_{\Theta}^{\prime}$ and halosteric $\eta_{S}^{\prime}$ components to separate the steric sea level changes associated with potential temperature $\Theta$ and salinity $S$ of seawater:

$\eta^{\prime}=\frac{1}{\rho_{0}} \int_{-H}^{0} \rho^{\prime} d z \approx \int_{-H}^{0}\left(\beta S^{\prime}-\alpha \Theta^{\prime}\right) d z=\eta_{S}^{\prime}+\eta_{\Theta}^{\prime}$. 
(a) MR Region A $\left(45^{\circ} \mathrm{E}-65^{\circ} \mathrm{E}, 15^{\circ} \mathrm{S}-5^{\circ} \mathrm{S}\right)$

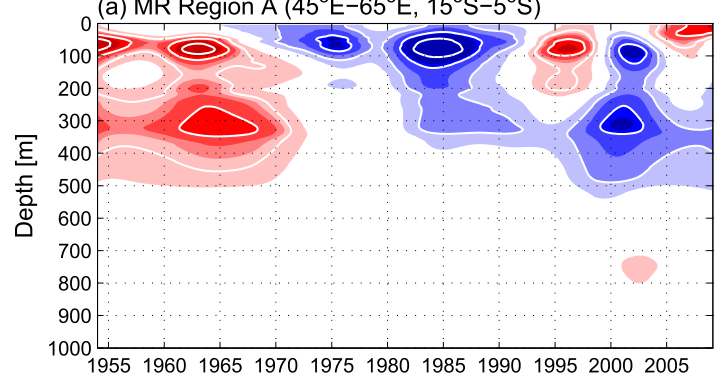

(b) WND Region A $\left(45^{\circ} \mathrm{E}-65^{\circ} \mathrm{E}, 15^{\circ} \mathrm{S}-5^{\circ} \mathrm{S}\right)$

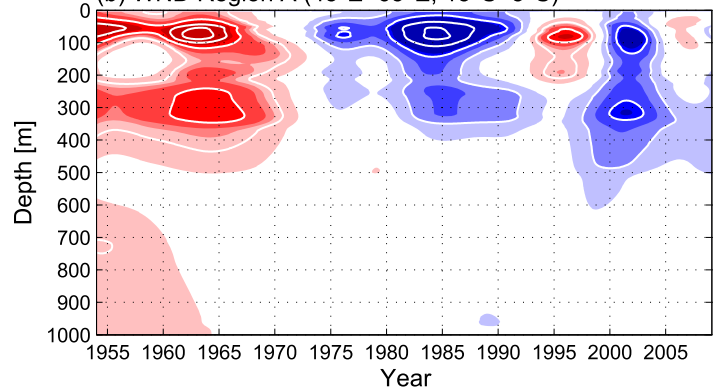

(c) MR Region $\mathrm{C}\left(50^{\circ} \mathrm{E}-70^{\circ} \mathrm{E}, 28^{\circ} \mathrm{S}-20^{\circ} \mathrm{S}\right)$

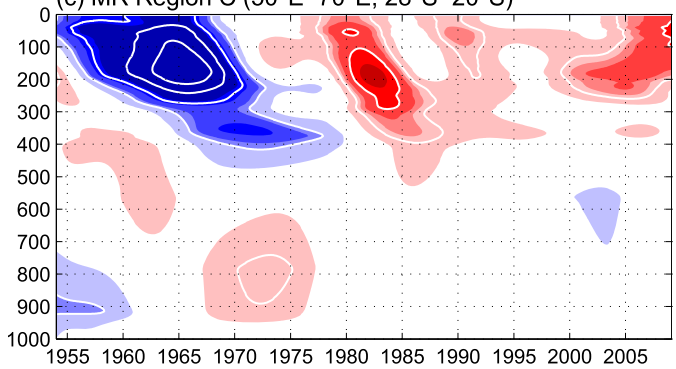

(d) WND Region $\mathrm{C}\left(50^{\circ} \mathrm{E}-70^{\circ} \mathrm{E}, 28^{\circ} \mathrm{S}-20^{\circ} \mathrm{S}\right)$

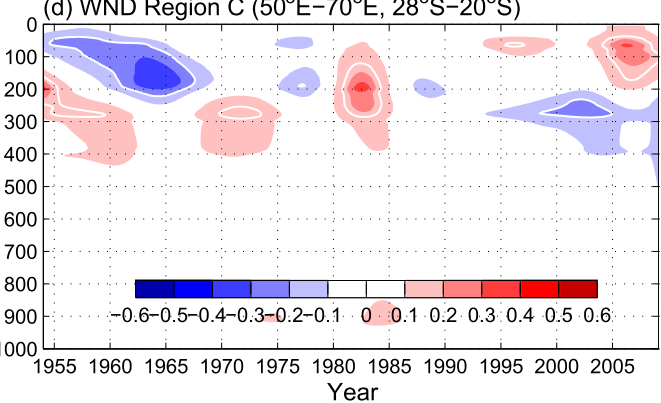

FIG. 8. Evolutions of 8-yr low-passed vertical potential temperature $\Theta$ anomaly $\left({ }^{\circ} \mathrm{C}\right)$ profile averaged over region A

$\left(15^{\circ}-5^{\circ} \mathrm{S}, 45^{\circ}-65^{\circ} \mathrm{E}\right)$ for (a) MR and (b) WND. (c),(d) As in (a) and (b) but for region $\mathrm{C}\left(28^{\circ}-20^{\circ} \mathrm{S}, 50^{\circ}-70^{\circ} \mathrm{E}\right)$.

In the above, $\rho^{\prime}$ and $\rho_{0}$ are density anomaly and reference density, $\alpha=-\rho^{-1} \partial \rho / \partial \theta$ and $\beta=\rho^{-1} \partial \rho / \partial S$ are the thermal expansion coefficient and saline contraction coefficient, and $H$ is the depth limit for vertical integration. Thermosteric SLA $\eta_{\Theta}^{\prime}$ integrated over the upper $2000 \mathrm{~m}[H=2000 \mathrm{~m}$ in Eq. (3)] has a similar amplitude to the total SLA $\eta^{\prime}$ for the entire water column, and the two are highly correlated at $r=$ 0.93 . Interestingly, $\eta_{\Theta}^{\prime}$ of the upper $300 \mathrm{~m}(H=300 \mathrm{~m})$ is also highly correlated with $\eta^{\prime}(r=0.96)$. This suggests that sea level variations in MR - WND are mainly caused by thermal variations in the upper $300 \mathrm{~m}$, and this is further confirmed by the high correlation between the heat content (HC) of $0-300 \mathrm{~m}$ and $\eta^{\prime}(r=0.98$; cf. Figs. 9a and 9c). On the other hand, halosteric SLA $\eta_{S}^{\prime}$ of $0-2000 \mathrm{~m}$ (Fig. 9d) shows only a slow decrease, while $\eta_{S}^{\prime}$ of $0-300 \mathrm{~m}$ varies little during the entire period. Halosteric SLA induced by deep-ocean salinity change only slightly compensates for the increasing trend due to thermal expansion. This result rules out the role of freshwater flux in generating the strong decadal sea level variability in region $\mathrm{C}$.

Next we examine how surface heat flux causes the upper-ocean $\mathrm{HC}$ variability in MR - WND by performing a heat budget analysis for the upper $300 \mathrm{~m}$ of region $\mathrm{C}$. The equation governing $\mathrm{HC}$ change is

$$
\frac{\partial \mathrm{HC}}{\partial t}=\mathrm{SHF}+\mathrm{ADV}+R
$$

where $\partial \mathrm{HC} / \partial t$ is the $\mathrm{HC}$ temporal tendency. SHF is the local surface heat flux forcing term as an aerial integration of net surface heat flux $Q_{\text {net }}$ over region C:

$$
\mathrm{SHF}=\iint_{\text {Area }} Q_{\mathrm{net}} d x d y
$$

ADV is the advection by ocean circulation estimated as the convergence of heat transports at the four lateral boundaries (i.e., $28^{\circ} \mathrm{S}, 20^{\circ} \mathrm{S}, 50^{\circ} \mathrm{E}$, and $70^{\circ} \mathrm{E}$ ) and at the base of the control volume $(H=300 \mathrm{~m})$. Following the method of Lee et al. (2004), we have

$$
\begin{aligned}
\mathrm{ADV}= & \iint_{28^{\circ} \mathrm{S}} \rho c_{p} v\left(\Theta-\Theta_{0}\right) d x d z-\iint_{20^{\circ} \mathrm{S}} \rho c_{p} v\left(\Theta-\Theta_{0}\right) d x d z+\iint_{50^{\circ} \mathrm{E}} \rho c_{p} u\left(\Theta-\Theta_{0}\right) d y d z \\
& -\iint_{70^{\circ} \mathrm{E}} \rho c_{p} u\left(\Theta-\Theta_{0}\right) d y d z+\iint_{\text {Area }} \rho c_{p} w_{-H}\left(\Theta-\Theta_{0}\right) d x d y
\end{aligned}
$$

where $u$ and $v$ are the zonal and meridional currents, $w_{-H}$ is the vertical velocity at $300 \mathrm{~m}$, and $\Theta_{0}$ is the reference temperature, which is calculated as the volume-mean potential temperature: 

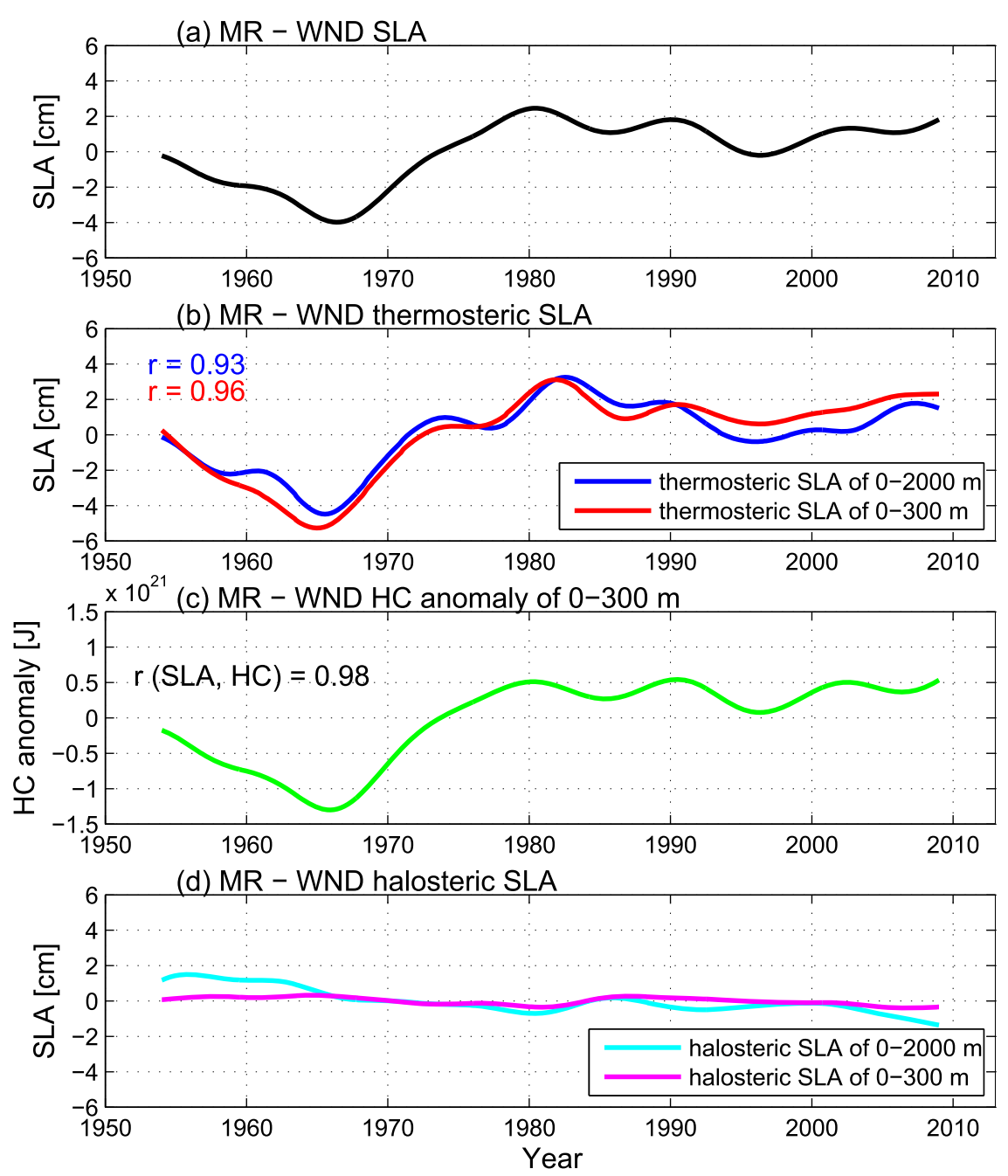

FIG. 9. The 8-yr low-passed variables from the MR - WND solution in region C: (a) SLA (cm), (b) thermosteric SLA (cm) of the upper $2000 \mathrm{~m}$ (blue) and upper $300 \mathrm{~m}$ (red), (c) total heat content anomaly (J) integrated over the upper $300 \mathrm{~m}$, and $(\mathrm{d})$ halosteric SLA $(\mathrm{cm})$ of the upper $2000 \mathrm{~m}$ (cyan) and upper $300 \mathrm{~m}$ (pink).

$$
\Theta_{0}(t)=\frac{\iiint \Theta(x, y, z, t) d x d y d z}{\iiint d x d y d z} .
$$

The residual term $R$ represents the effects of unresolved terms, such as mixing and diffusion and errors resulting from the calculation of other terms. It is estimated simply as $R=\partial \mathrm{HC} / \partial t-\mathrm{SHF}-\mathrm{ADV}$. As a validation for the method, we checked the mean seasonal cycle of heat budget (Fig. S7 in the supplementary material). In region $\mathrm{C}$, the $\mathrm{HC}$ seasonal cycle is primarily controlled by the surface heat flux. Ocean advection plays a secondary role, and it mainly induces warming in austral winter, which partly mitigates the cooling by heat flux.
Term $R$ is one order of magnitude smaller than the other terms, lending us the confidence to further investigate decadal variability with the heat budget analysis.

The 8-yr low-pass-filtered heat budget highlights signals at a decadal time scale (Fig. 10a). In the MR WND solution, both SHF (red) and ADV (blue) exhibit strong variations and significant correlations with $\partial \mathrm{HC} / \partial t$ ( $r=0.46$ and $r=0.62$, respectively). Most of the $\mathrm{HC}$ changes can be well explained by the two terms. Specifically, the negative $\partial \mathrm{HC} / \partial t$ during $1955-65$ and positive $\partial \mathrm{HC} / \partial t$ during $1965-80$ are likely contributed by both SHF and ADV, whereas the HC changes after 1985 are mainly induced by ADV. ADV has a larger magnitude and a higher correlation with $\partial \mathrm{HC} / \partial t$ than SHF, indicating a larger contribution of heat advection by 

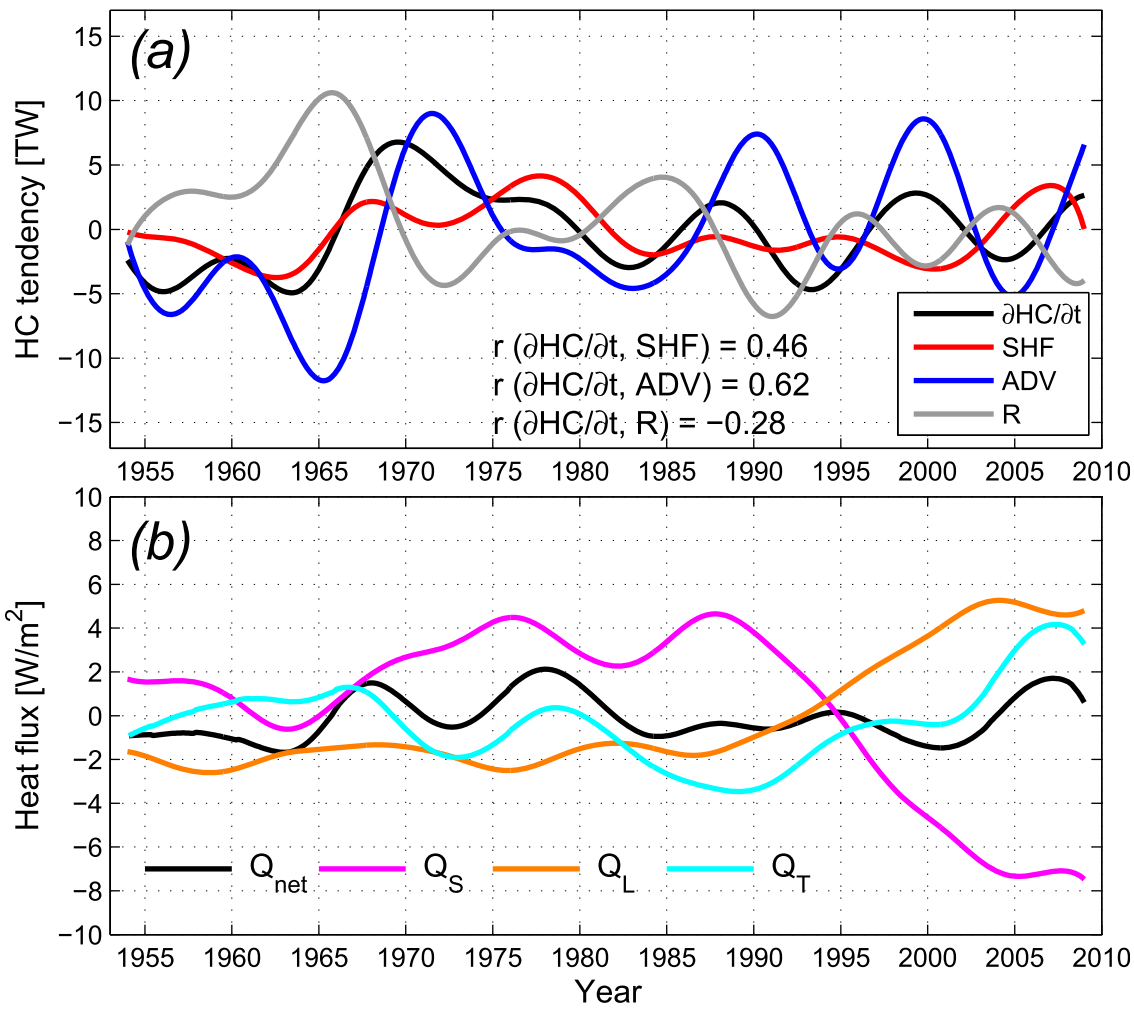

FIG. 10. Decadal (8-yr low-passed) heat budget of the upper $300 \mathrm{~m}$ of region $\mathrm{C}$ from the MR - WND solution: (a) heat content tendency $\partial \mathrm{HC} / \partial t$ (TW; black), surface heat flux term SHF (red), advection term ADV (blue), and residual term $R$ (gray). (b) Decadal anomalies (8-yr low-passed) of net surface heat flux $Q_{\text {net }}\left(\mathrm{W} \mathrm{m}^{-2}\right.$; black), shortwave radiation $Q_{S}$, longwave radiation $Q_{L}$, and turbulent heat flux $Q_{T}$ averaged over region C.

ocean circulation than local surface heating. Note that by taking the difference MR - WND, advection of mean temperature by wind-driven anomalous currents $\left(\mathbf{u}^{\prime} \cdot \nabla \Theta^{m}\right.$ process) has been removed. The ADV term here primarily quantifies the heat-flux-forced anomalous temperature advected by the mean and anomalous currents (i.e., $\mathbf{u}^{m}$. $\nabla \Theta^{\prime}$ and $\left.\mathbf{u}^{\prime} \cdot \nabla \Theta^{\prime}\right)$. To identify this effect, the mean current structures at the lateral boundaries of region $\mathrm{C}$ are displayed in Fig. $\mathrm{S} 8$ of the supplementary material. There is a net meridional convergence in the near-surface layer, with the southward Ekman flow at $20^{\circ} \mathrm{S}$ much larger than at $28^{\circ} \mathrm{S}$. In the zonal direction, strong eastward flows $\left(>5 \mathrm{~cm} \mathrm{~s}^{-1}\right)$ associated with the South Indian Countercurrent (Siedler et al. 2006) exist in the upper $100 \mathrm{~m}$. Through these flows, $\Theta$ anomalies produced by heat fluxes out of region $\mathrm{C}$ are brought in and affect the upper-ocean $\mathrm{HC}$ of the region. Therefore, the surface heat flux affects the heat content and thermosteric sea level variability of region $\mathrm{C}$ through both local surface heating and heat redistribution by ocean currents.

As opposed to that of the seasonal cycle, the residual term $R$ here is large in magnitude. A close inspection, however, suggests that the evolution of $R$ is generally out of phase with $\partial \mathrm{HC} / \partial t$, with a linear correlation of -0.28 . This means that $R$ represents a damping process rather than a driving process for $\mathrm{HC}$ variability. In fact, $R$ has a much higher correlation with ADV $(r=-0.84)$, and the correlation reaches -0.88 when $R$ lags ADV by 7 months. The correlation between SHF and $R$ is insignificant. Therefore, $R$ variations arise mainly from the ADV term. Their negative correlation suggests that variations in $R$ may result from the overestimation of ADV signals through Eq. (6). Alternatively, the lagging relationship indicates that $R$ may also represent the mixing and diffusion processes missed in Eq. (4). HC anomalies brought by ADV are dissipated by these processes shortly thereafter.

Given the importance of surface heat flux forcing, we further examine variations of its components-namely, shortwave radiation $Q_{S}$, longwave radiation $Q_{L}$, and turbulent (sensible plus latent) heat flux $Q_{T}$ (Fig. 10b). The terms $Q_{S}$ and $Q_{L}$ largely compensate each other in causing decadal $Q_{\text {net }}$ variability, while $Q_{T}$ shows the best consistency with $Q_{\text {net }}$ in both amplitude and phase. Further analysis suggests that $Q_{T}$ variability is mainly caused by wind speed variations (not shown). These 
(a) stochastic winds

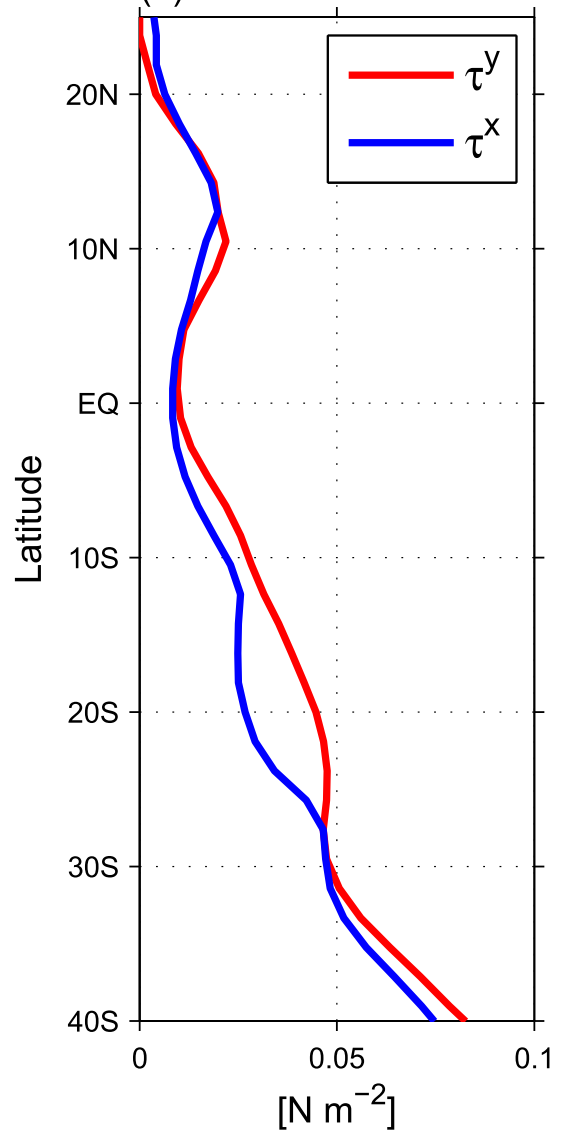

(b) SLA

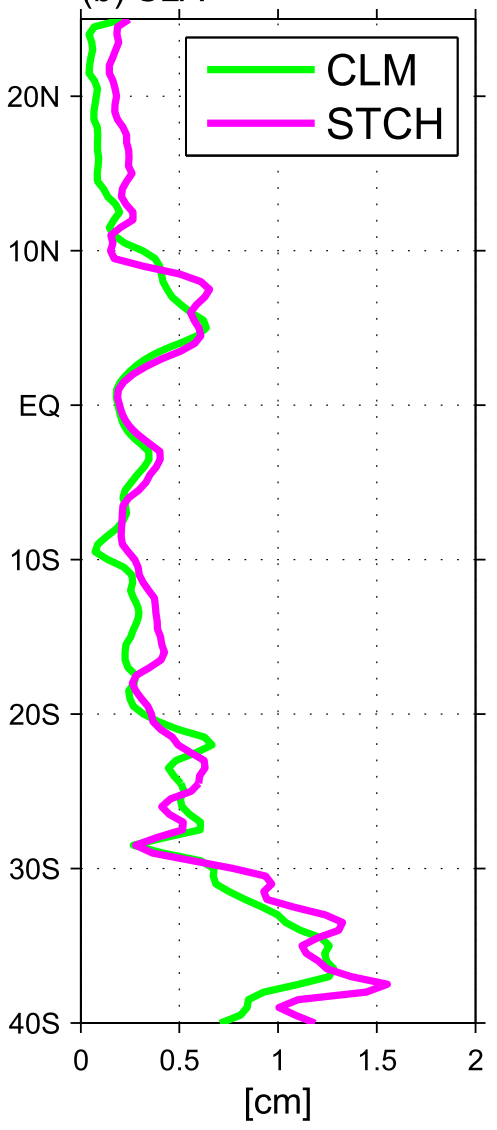

(c) $\operatorname{STD}(\mathrm{STCH})-\mathrm{STD}(\mathrm{CLM})$

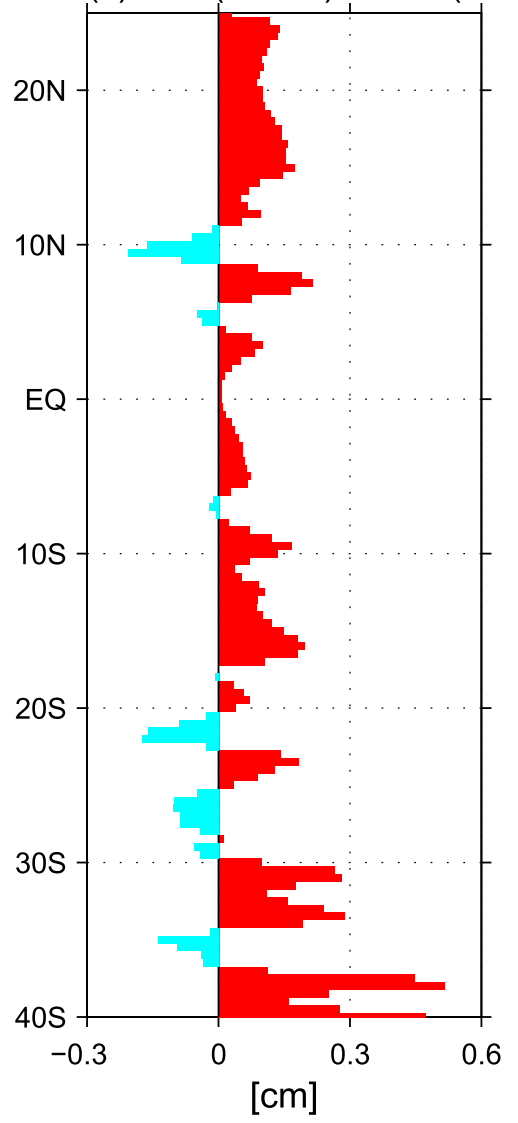

FIG. 11. Meridional distributions of (a) STD of zonal (blue) and meridional (red) stochastic wind stress averaged for $50^{\circ}-70^{\circ} \mathrm{E},(\mathrm{b}) \mathrm{STD}$ values of decadal SLA averaged for $50^{\circ}-70^{\circ} \mathrm{E}$ from STCH (pink) and CLM (green), and (c) their difference STD(STCH) - STD(CLM).

results suggest that in the subtropical IO, surface winds affect decadal sea level variability through two comparable effects: wind stress-driven ocean dynamics and wind speed-controlled surface turbulent heat flux. This is different from that of the tropics where wind stress is the dominant forcing.

\section{c. Region D and stochastic wind forcing}

Stochastic wind forcing obtains its maximal effect in the southwestern subtropical IO (Fig. 6c). One reason for the enhanced effect there is the large amplitude of stochastic winds, which has been indicated by the distribution of storm activity (Fig. 1) and stochastic wind variance (Figs. S1-S3). Within $50^{\circ}-70^{\circ} \mathrm{E}$, the STD of zonal mean stochastic wind stress increases from $0.01 \mathrm{~N} \mathrm{~m}^{-2}$ at the equator to $0.05 \mathrm{~N} \mathrm{~m}^{-2}$ at $30^{\circ} \mathrm{S}$ and reaches as large as $0.07-0.08 \mathrm{~N} \mathrm{~m}^{-2}$ at $35^{\circ} \mathrm{S}$ (Fig. 11a). Correspondingly, the STD of decadal SLA in the STCH run also increases southward with increasing latitude (pink in Fig. 11b). However, SLA of STCH contains variability induced by ocean internal variability, which also has maximum power between $40^{\circ}$ and $30^{\circ} \mathrm{S}$, as measured by the STD of the CLM run (green in Fig. 11b). The net stochastic wind forcing effect can be roughly represented by STD(STCH) - STD(CLM), which is positive at most latitudes (Fig. 11c), suggesting the enhancement of decadal SLA by stochastic winds. There are also several latitude bands in which STD $(\mathrm{STCH})-\mathrm{STD}(\mathrm{CLM})$ is negative. This is not surprising, given that in some regions the stochastic wind forcing effect and its interaction with ocean internal variability may have an opposite sign from the ocean internal variability effect. In general, STD(STCH) STD (CLM) shows an increasing trend from the equator to higher latitudes, consistent with the meridional distribution of the strength of stochastic winds.

The enhanced stochastic forcing effect south of $30^{\circ} \mathrm{S}$ (Figs. 6c and 11) marks region D as an ideal place for further investigating stochastic wind forcing and its interaction with other processes. Our HYCOM simulation, however, shows large discrepancies from AVISO and ORA-S4 data in the southwestern subtropical IO 
(a) MR

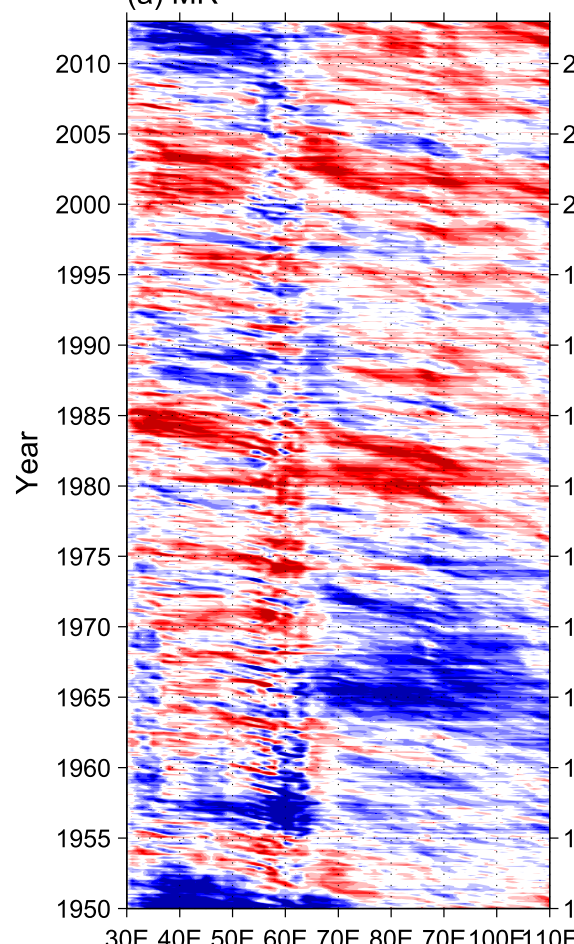

(b) $\mathrm{STCH}$

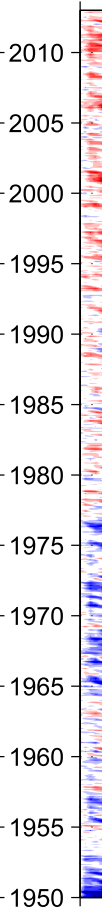

(c) CLM

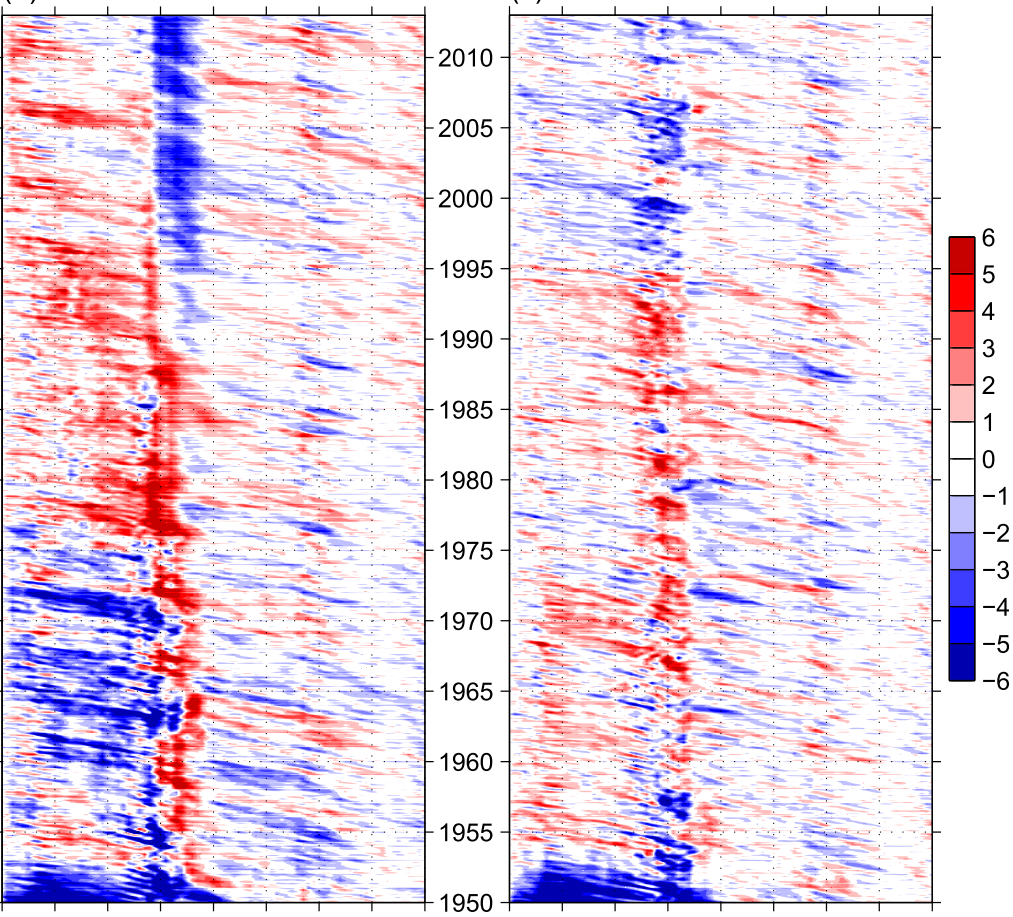

FIG. 12. Time-longitude plots of monthly SLA (cm) averaged between $35^{\circ}$ and $30^{\circ} \mathrm{S}$ for (a) MR, (b) STCH, and (c) CLM.

(Figs. 2-5). The simulated decadal sea level variations in region $\mathrm{D}$ are not consistent with these data (Fig. 5), which is partly due to the unpredictable nature of stochastic forcing and ocean internal instabilities dominating the sea level variability there. Additional comparison is needed to validate the model performance in region D. Vertical thermal stratification is closely associated with sea level variability through the thermosteric effect. Comparisons with WOAO9 climatology (Fig. S9 in the supplementary material) suggest that HYCOM can realistically represent the mean vertical temperature structure and its seasonal cycle in region $\mathrm{D}$, although some noisy structures are seen near the southern boundary (Fig. S9d). To some extent, this result provides confidence for the model simulation of the mean ocean state of region D. Nevertheless, keep in mind that the analysis and discussion for region $\mathrm{D}$ below contains a larger degree of uncertainty than that for other regions.

Figure 12a shows the time-longitude structure of the unfiltered monthly SLA from the MR, which is averaged over the latitude range of region $\mathrm{D}\left(35^{\circ}-30^{\circ} \mathrm{S}\right)$. Signals at various time scales exhibit clear westward movement across the IO basin, reflecting the propagation of Rossby waves and mesoscale eddies. Albeit in monthly resolution, higher-frequency signals (periods of a few months) representing mesoscale eddy variability are prominent, especially in the area west of $60^{\circ} \mathrm{E}$. Eddies and decadal time scale SLAs generated near $60^{\circ} \mathrm{E}$ further propagate to the western IO and influence sea level variations there. Monthly SLAs from AVISO data during 19922012 exhibit some similar characteristics (Fig. S10). Consistent with our model results, the observed mesoscale eddy signals are also enhanced in the western IO basin. Without the forcing of climate modes, SLAs in the STCH run are considerably altered (Fig. 12b). Lowfrequency signals in the STCH run are significantly reduced in the central-to-eastern basin but still prominent in the western basin. Without any form of external forcing, SLAs of the CLM run also show largeamplitude variability in the western basin (Fig. 12c) due to the enhancement of mesoscale eddy variability. Interestingly, SLAs of STCH are much stronger than those of CLM in the western basin. The enhanced signals in STCH are mainly generated between $50^{\circ}$ and $70^{\circ} \mathrm{E}$. There is no evident westward intensification of stochastic winds at these latitudes (Fig. S1). The enhancement in the western basin may be partly attributed to the constructive accumulation of forced variability along the Rossby wave characteristics. However, both STCH and WND show an energy jump at around $60^{\circ} \mathrm{E}$, indicating that the enhanced stochastic wind forcing 
(a) MR SLA \& $Q_{\text {net }}$

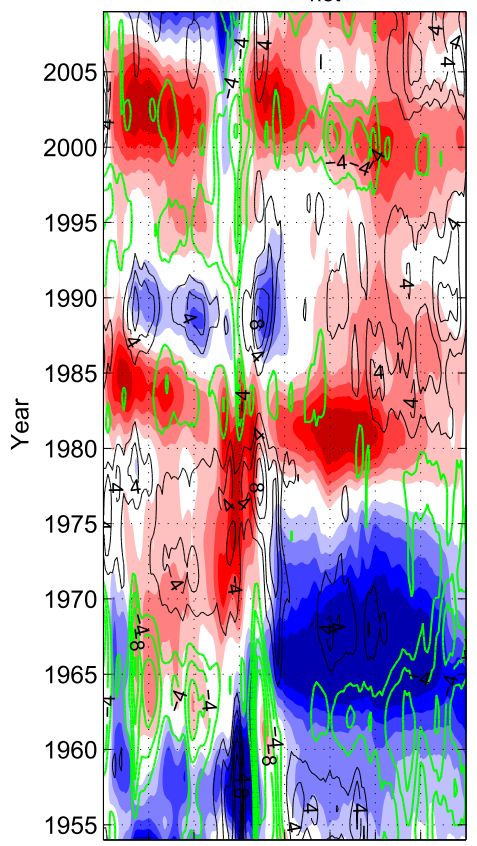

(b) WND SLA \& $W_{E}$

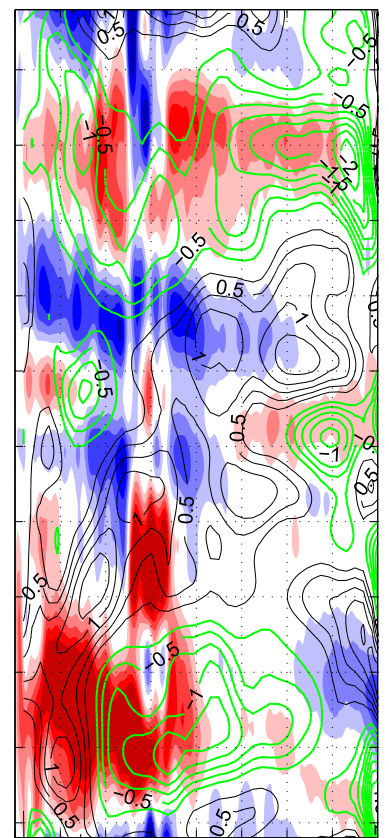

(c) STCH SLA

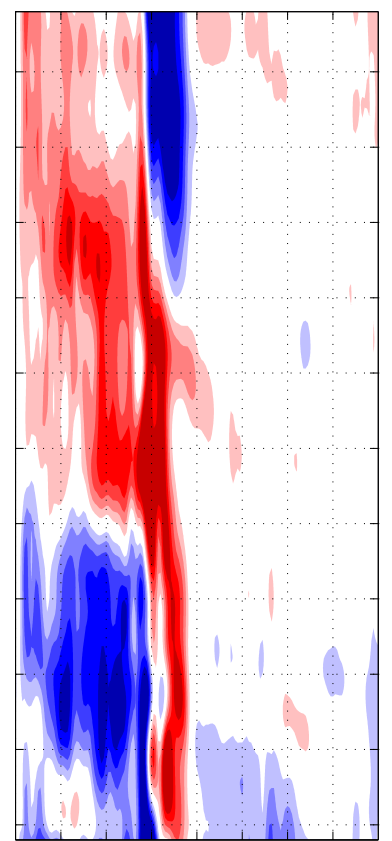

(d) CLM SLA

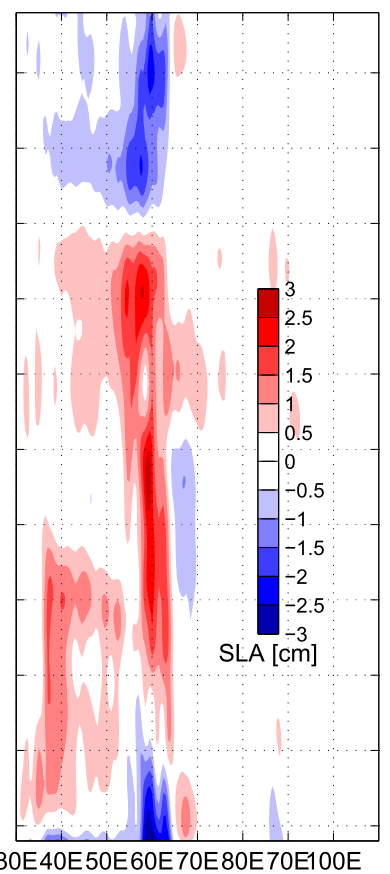

FIG. 13. Time-longitude plots of 8-yr low-passed SLA (color shading) averaged between $35^{\circ}$ and $30^{\circ} \mathrm{S}$ for (a) MR, (b) WND, (c) STCH, and (d) CLM. Contours in (a) denote 8-yr low-passed net surface heat flux $Q_{\text {net }}$ anomaly ( $\mathrm{W} \mathrm{m}^{-2}$; black for positive and green for negative; contour interval $2 \mathrm{~W} \mathrm{~m}^{-2}$ ), while those in (b) denote 8-yr low-passed Ekman pumping velocity $W_{E}$ anomaly $\left(10^{-7} \mathrm{~m} \mathrm{~s}^{-1}\right.$; black for positive and green for negative; contour interval $\left.0.25 \times 10^{-7} \mathrm{~m} \mathrm{~s}^{-1}\right)$.

effect is likely associated with ocean internal variability. As stochastic winds are imposed on the dynamically unstable ocean, their interaction can have a strong rectification of low-frequency ocean variability through nonlinear effects.

To underscore decadal time-scale variations, Fig. 13 shows 8-yr low-pass-filtered SLA maps of different solutions. Decadal variations of wind stress induced Rossby waves propagating from the central to western basin are evident, which is clearly discernible in the WND run (Fig. 13b). Here we use the Ekman pumping velocity $W_{E}=\operatorname{curl}(\tau / f) \rho_{0}^{-1}$ (where $f$ is the Coriolis parameter, and $\rho_{0}=1025 \mathrm{~kg} \mathrm{~m}^{-3}$ is the mean seawater density of the Ekman layer) to represent the forcing effect of wind stress on the ocean. Specifically, basinscale negative Ekman pumping velocity anomalies during the 1950s-1960s and 1990s-2000s generate downwelling Rossby waves (indicated by positive SLAs), while the positive $W_{E}$ anomalies during the 1970s-1980s and after 2005 produce upwelling Rossby waves. The wind-driven Rossby waves, however, are merely one of the major processes inducing decadal SLAs. Surface heat flux (contours in Fig. 13a) can also cause decadal SLAs in the MR. For example, the strong, long-lasting negative SLAs in the central-eastern basin during the 1960s-1970s are likely caused by the surface heat loss (negative $Q_{\text {net }}$ anomaly) from 1955 through 1965. Stochastic wind forcing has a large influence on decadal SLAs in the western IO basin, strengthening (weakening) the positive (negative) SLAs from 1975 onward and enhancing the negative (positive) SLAs before 1975 (Figs. 13a,c). Ocean internal variability also has a significant influence on decadal SLAs in the western basin, especially near $60^{\circ} \mathrm{E}$ (Fig. $13 \mathrm{~d}$ ), but this effect is smaller than stochastic wind forcing. The strong decadal variability between $50^{\circ}$ and $70^{\circ} \mathrm{E}$ reflects mainly the decadal meridional displacement of the zonal SSH front lying between the high-SSH area in the north and low-SSH area in the south (Fig. 2). The interaction between strong stochastic winds and the dynamical instability of the front gives rise to large-amplitude decadal variations in sea level and ocean circulation. These complicated processes should be given more indepth investigation in the future.

\section{Summary and discussion}

The Indian Ocean (IO) is the home for many lowlying islands and heavily populated coastal zones, which are vulnerable to landmass erosion by sea level rise. 
Regional sea level variability in the IO under the changing climate is drawing increasing attention from climate researchers and policy-makers. Here we explore the causes of decadal sea level changes in the IO during 1950-2012 using the HYCOM model forced by NCEPNCAR reanalysis atmospheric data. A series of parallel HYCOM experiments are performed to assess effects from different processes, including those rarely investigated before, such as heat flux, stochastic wind forcing, and ocean internal (unforced) variability. The primary findings of our analysis are summarized as follows:

1) The HYCOM-simulated sea level variability is compared with AVISO satellite altimeter data and ECMWF ORA-S4 data to evaluate the model performance. It is shown that HYCOM is capable of reproducing most of the sea level variations in the western-to-central IO basin. In the southeastern IO, however, HYCOM fails to capture some of the sea level variations, especially those off the western Australian coast. This is due to the absence of the remote wind forcing effect from the Pacific Ocean through the ITF variability in our simulation of the IO basin alone. Therefore, our analysis is confined to the western-to-central basin of the IO.

2) Analysis of the outputs of the HYCOM experiments reveals a large spatial diversity in the mechanisms of decadal sea level variability. Sea level variations in the tropical IO north of $20^{\circ} \mathrm{S}$, especially the maximum variability in the south IO thermocline ridge region, are primarily induced by the decadal surface wind forcing of climate modes. Other effects are generally much smaller. In comparison, the mechanism in the subtropical IO south of $20^{\circ} \mathrm{S}$ is more complex, with significant effects from different processes.

3) Surface heat and freshwater fluxes are important in the subtropical south IO and near the coast of the Indian subcontinent. Ocean internal processes have considerable contribution along the Somali coast and in the western Bay of Bengal and the subtropical south IO. Stochastic wind forcing by storm tracks, tropical cyclones, and intraseasonal oscillations is also not negligible in producing large-scale SLAs. It achieves the maximum effect in the southwestern subtropical IO.

4) In the subtropical IO between $28^{\circ}$ and $20^{\circ} \mathrm{S}$, a large portion of sea level variability is not explained by the wind stress effect. Instead, these sea level variations are closely associated with upper-ocean thermal structure changes in response to surface heat flux forcing. A heat budget analysis for the upper $300 \mathrm{~m}$ of this region reveals that surface heat flux affects thermosteric sea level variability mainly through heat advection of ocean circulation and to a lesser extent through local surface heating.

5) The effect of stochastic wind forcing generally increases from the equator to higher latitudes, following the intensity distribution of stochastic winds. Its enhanced effect in the southwestern IO south of $30^{\circ} \mathrm{S}$ is likely associated with strong ocean internal instability. Nonlinear interaction between stochastic wind forcing and the dynamically unstable ocean can leave strong rectification onto the decadal variability of regional sea level and circulation.

While most existing studies emphasize the wind stress effect, our analysis reveals significant effects from heat flux, ocean internal variability, and stochastic atmospheric forcing on regional sea level variability. However, more accurate estimates of these effects should be done over the global ocean in future research, including the effects of interbasin exchanges with the Pacific, Atlantic, and Southern Oceans. These exchanges are excluded in our IO-basin-alone model configuration. The ITF transport is especially important in regulating the IO circulation and sea level structures. Remotely forced variability and its interaction with local processes can alter the mechanism of decadal sea level variability in various ways. Besides a direct forcing impact, the activity of ocean internal variability is modulated by the time-varying ocean circulation. Stochastic wind forcing in other ocean basins, which is stronger than in the IO, can also influence the IO through ocean teleconnection.

Compared with other regions, our findings in region $\mathrm{D}$ (southwestern subtropical IO) and the stochastic wind forcing effect are more open to dispute. In our results, both ocean internal variability and stochastic wind forcing achieve the largest effect in region $\mathrm{D}$. The two effects and their interaction are unpredictable for an ocean model, which is a major cause for the large model-data discrepancies there. The large ocean internal variability effect is supported by existing observational research (e.g., van Ballegooyen et al. 1994; Biastoch and Krauss 1999), while the large stochastic wind forcing effect is to some extent guaranteed by the strong stochastic atmospheric variability at midlatitudes (Figs. 1, 11, S1, and S2). However, the interaction between the dynamically unstable ocean and stochastic forcing is an issue of high complexity and uncertainty. The resultant sea level variability could be sensitive to the choice of the initial condition and the random time coefficient $R_{n}$ in Eq. (2). In this sense, our STCH simulation represents merely one of many possibilities. It is hard to say whether the amplitude of decadal sea level 
variability will be dramatically different if we adopt another initial condition or another permutation of $R_{n}$. To achieve an unambiguous and in-depth understanding, these issues should be examined in future research.

In many areas of the IO, ocean internal variability plays a vital role in regional sea level and circulation variability. Its representation in the OGCM, however, is sensitive to the model resolution. Our horizontal resolution of $0.25^{\circ}$ is eddy permitting rather than eddy resolving. Simulations with higher resolutions (such as $1 / 10^{\circ}$ or $1 / 12^{\circ}$ ) may better quantify the ocean internal variability effect and its interactions with other processes (e.g., Sérazin et al. 2015), although an overly fine resolution can draw the model ocean to a turbulent dynamical state. We also found a significant impact of surface heat/freshwater fluxes on decadal SLA in some regions. Among others, the subtropical south IO between $28^{\circ}$ and $20^{\circ} \mathrm{S}$ is shown to be significantly affected by heat flux forcing. Although most low-frequency SLAs in the IO are of thermosteric origin, the contribution of freshwater flux through the halosteric effect can also be significant in some areas, such as the southeastern tropical IO (e.g., Nidheesh et al. 2013; Llovel and Lee 2015). Experiments that isolate the effects of heat versus freshwater fluxes should be performed in future research. Regarding stochastic atmospheric forcing, we merely examine the wind stress effect. Stochastic forcing via surface heat and freshwater fluxes may also cause sea level changes. Note that both stochastically forced and internally generated decadal SLAs are unpredictable. The large-amplitude unpredictable part of decadal sea level variability in the midlatitude region points to the need for further improving our understanding of its effects in order to promote the decadal prediction research of the climate community.

Acknowledgments. This study is supported by NSF CAREER Award 0847605, the NSF AGS Climate and Large-Scale Dynamics Program Award 1446480, and the NASA Ocean Vector Wind Science Team Award NNX14AM68G. Insightful comments from four reviewers were very helpful for improving the manuscript. We appreciate the NCAR CISL and the Office of Information Technology (OIT) of University of Colorado for providing and maintaining the computational resource.

The monthly MEI time series is adopted from CPC of NOAA (http://www.cpc.ncep.noaa.gov); DMI is taken from the Frontier Research Center for Global Change of JAMSTEC (http://www.jamstec.go.jp/frsgc/research/d1/ iod/); NCEP-NCAR reanalysis data are downloaded from the NOAA/ESRL website (http://www.esrl.noaa. gov/); AVISO satellite altimeter sea level data are downloaded from their website (http://www.aviso.oceanobs. com/); ORA-S4 data are provided by ECMWF (http:// icdc.zmaw.de/easy_init_ocean.html?\&L=1); WOA09 temperature and salinity climatology are provided by NOAA's National Oceanographic Data Center (NODC) (https://www.nodc.noaa.gov/OC5/WOA09/pr_woa09.html); data analysis and graphing work in this study were completed with a licensed Matlab program.

\section{REFERENCES}

Alexander, M. A., 2010: Extratropical air-sea interaction, sea surface temperature variability, and the Pacific decadal oscillation. Climate Dynamics: Why Does Climate Vary? Geophys. Monogr., Vol. 189, Amer. Geophys. Union, 123-148, doi:10.1029/ 2008GM000794.

_ L. Latrosova, C. Penland, J. D. Scott, and P. Chang, 2008: Forecasting Pacific SSTs: Linear inverse model predictions of the PDO. J. Climate, 21, 385-402, doi:10.1175/2007JCLI1849.1.

Alory, G., S. Wijffels, and G. Meyers, 2007: Observed temperature trends in the Indian Ocean over 1960-1999 and associated mechanisms. Geophys. Res. Lett., 34, L02606, doi:10.1029/ 2006 GL028044.

Antonov, J. I., and Coauthors, 2010: Salinity. Vol. 2, World Ocean Atlas 2009, S. Levitus, Ed., NOAA Atlas NESDIS 69, 184 pp.

Balmaseda, M. A., K. Mogensen, and A. T. Weaver, 2013: Evaluation of the ECMWF ocean reanalysis system ORAS4. Quart. J. Roy. Meteor. Soc., 139, 1132-1161, doi:10.1002/qj.2063.

Barnett, T. P., D. W. Pierce, K. M. AchutaRao, P. J. Gleckler, B. D. Santer, J. M. Gregory, and W. M. Washington, 2005: Penetration of human-induced warming into the world's oceans. Science, 309, 284-287, doi:10.1126/science.1112418.

Beal, L. M., and Coauthors, 2011: On the role of the Agulhas system in ocean circulation and climate. Nature, 472, 429-436, doi:10.1038/nature09983.

Biastoch, A., and W. Krauss, 1999: The role of mesoscale eddies in the source regions of the Agulhas Current. J. Phys. Oceanogr., 29, 2303-2317, doi:10.1175/1520-0485(1999)029<2303: TROMEI $>2.0 . \mathrm{CO} ; 2$.

Bindoff, N. L., and Coauthors, 2007: Observations: Oceanic climate change and sea level. Climate Change 2007: The Physical Science Basis, S. Solomon et al., Eds., Cambridge University Press, 385-432.

Birol, F., and R. Morrow, 2001: Source of the baroclinic waves in the southeast Indian Ocean. J. Geophys. Res., 106, 9145-9160, doi:10.1029/2000JC900044.

Blanke, B., J. D. Neelin, and D. Gutzler, 1997: Estimating the effect of stochastic wind stress forcing on ENSO irregularity. J. Climate, 10, 1473-1486, doi:10.1175/1520-0442(1997)010<1473: ETEOSW $>2.0 . \mathrm{CO} ; 2$.

Bleck, R., 2002: An oceanic general circulation model framed in hybrid isopycnic-Cartesian coordinates. Ocean Modell., 4, 5588, doi:10.1016/S1463-5003(01)00012-9.

Cai, W., G. Meyers, and G. Shi, 2005: Transmission of ENSO signal to the Indian Ocean. Geophys. Res. Lett., 32, L05616, doi:10.1029/2004GL021736.

Chen, G., D. Wang, and Y. Hou, 2012: The features and interannual variability mechanism of mesoscale eddies in the Bay of Bengal. Cont. Shelf Res., 47, 178-185, doi:10.1016/ j.csr.2012.07.011.

Chhak, K. C., A. M. Moore, and R. F. Milliff, 2009: Stochastic forcing of ocean variability by the North Atlantic Oscillation. J. Phys. Oceanogr., 39, 162-184, doi:10.1175/2008JPO3972.1. 
Church, J. A., and Coauthors, 2013: Sea level change. Climate Change 2013: The Physical Science Basis, T. F. Stocker et al., Eds., Cambridge University Press, 1137-1216. [Available online at http://www.climatechange2013.org/images/report/ WG1AR5_Chapter13_FINAL.pdf.]

- , N. J. White, R. Coleman, K. Lambeck, and J. X. Mitrovica, 2004: Estimates of the regional distribution of sea level rise over the 1950-2000 period. J. Climate, 17, 2609-2625, doi:10.1175/1520-0442(2004)017<2609:EOTRDO>2.0.CO;2.

- J. M. Gregory, N. J. White, S. M. Platten, and J. X. Mitrovica, 2011: Understanding and projecting sea level change. Oceanography, 24, 130-143, doi:10.5670/oceanog.2011.33.

Clarke, A. J., and X. Liu, 1994: Interannual sea level in the northern and eastern Indian Ocean. J. Phys. Oceanogr., 24, 1224-1235, doi:10.1175/1520-0485(1994)024<1224:ISLITN>2.0.CO;2.

Dai, A., T. Qian, K. E. Trenberth, and J. D. Milliman, 2009: Changes in continental freshwater discharge from 1948 to 2004. J. Climate, 22, 2773-2792, doi:10.1175/2008JCLI2592.1.

Ducet, N., P. Le Traon, and G. Reverdin, 2000: Global highresolution mapping of ocean circulation from TOPEX/ Poseidon and ERS-1 and -2. J. Geophys. Res., 105, $19477-$ 19498, doi:10.1029/2000JC900063.

England, M. H., and Coauthors, 2014: Recent intensification of winddriven circulation in the Pacific and the ongoing warming hiatus. Nat. Climate Change, 4, 222-227, doi:10.1038/nclimate2106.

Fairall, C., E. F. Bradley, J. Hare, A. Grachev, and J. Edson, 2003: Bulk parameterization of air-sea fluxes: Updates and verification for the COARE algorithm. J. Climate, 16, 571-591, doi:10.1175/1520-0442(2003)016<0571:BPOASF > 2.0.CO;2.

Feng, M., G. Meyers, A. Pearce, and S. Wijffels, 2003: Annual and interannual variations of the Leeuwin Current at $32^{\circ} \mathrm{S}$. J. Geophys. Res., 108, 3355, doi:10.1029/2002JC001763.

_ , Y. Li, and G. Meyers, 2004: Multidecadal variations of Fremantle sea level: Footprint of climate variability in the tropical Pacific. Geophys. Res. Lett., 31, L16302, doi:10.1029/2004GL019947.

_- M. J. McPhaden, and T. Lee, 2010: Decadal variability of the Pacific subtropical cells and their influence on the southeast Indian Ocean. Geophys. Res. Lett., 37, L09606, doi:10.1029/ 2010GL042796.

, C. Böning, A. Biastoch, E. Behrens, E. Weller, and Y. Masumoto, 2011: The reversal of the multi-decadal trends of the equatorial Pacific easterly winds, and the Indonesian Throughflow and Leeuwin Current transports. Geophys. Res. Lett., 38, L11604, doi:10.1029/2011GL047291.

Flügel, M., P. Chang, and C. Penland, 2004: The role of stochastic forcing in modulating ENSO predictability. J. Climate, 17, 3125 3140, doi:10.1175/1520-0442(2004)017<3125:TROSFI >2.0.CO;2.

Frankignoul, C., and K. Hasselmann, 1977: Stochastic climate models, Part II: Application to sea-surface temperature anomalies and thermocline variability. Tellus, 29A, 289-305, doi:10.1111/j.2153-3490.1977.tb00740.x

_ - P. Müller, and E. Zorita, 1997: A simple model of the decadal response of the ocean to stochastic wind forcing. J. Phys. Oceanogr., 27, 1533-1546, doi:10.1175/1520-0485(1997)027<1533: ASMOTD $>2.0 . C O ; 2$.

Fritz, H. M., C. D. Blount, S. Thwin, M. K. Thu, and N. Chan, 2009: Cyclone Nargis storm surge in Myanmar. Nat. Geosci., 2, 448449, doi:10.1038/ngeo558.

Gordon, A. L., 1985: Indian-Atlantic transfer of thermocline water at the Agulhas retroflection. Science, 227, 1030-1033, doi:10.1126/science.227.4690.1030.

Hamlington, B. D., R. R. Leben, R. S. Nerem, W. Han, and K. Y. Kim, 2011: Reconstructing sea level using cyclostationary empirical orthogonal functions. J. Geophys. Res. Oceans, 116, C12015, doi:10.1029/2011jc007529.

Han, W., 2005: Origins and dynamics of the 90-day and 30-60-day variations in the equatorial Indian Ocean. J. Phys. Oceanogr., 35, 708-728, doi:10.1175/JPO2725.1.

, and P. J. Webster, 2002: Forcing mechanisms of sea level interannual variability in the Bay of Bengal. J. Phys. Oceanogr., 32, 216-239, doi:10.1175/1520-0485(2002)032<0216: FMOSLI $>2.0 . \mathrm{CO} ; 2$.

- , G. A. Meehl, and A. Hu, 2006a: Interpretation of tropical thermocline cooling in the Indian and Pacific Oceans during recent decades. Geophys. Res. Lett., 33, L23615, doi:10.1029/ 2006GL027982.

— T. Shinoda, L. L. Fu, and J. P. McCreary, 2006b: Impact of atmospheric intraseasonal oscillations on the Indian Ocean dipole during the 1990s. J. Phys. Oceanogr., 36, 670-690, doi:10.1175/JPO2892.1.

, and Coauthors, 2010: Patterns of Indian Ocean sea-level change in a warming climate. Nat. Geosci., 3, 546-550, doi:10.1038/ngeo 901 .

, and Coauthors, 2014a: Intensification of decadal and multidecadal sea level variability in the western tropical Pacific during recent decades. Climate Dyn., 43, 1357-1379, doi:10.1007/s00382-013-1951-1.

, J. Vialard, M. J. McPhaden, T. Lee, Y. Masumoto, M. Feng, and W. P. M. de Ruijter, 2014b: Indian Ocean decadal variability: A review. Bull. Amer. Meteor. Soc., 95, 1679-1703, doi:10.1175/BAMS-D-13-00028.1.

Hasselmann, K., 1976: Stochastic climate models, Part I: Theory. Tellus, 28A, 473-485, doi:10.1111/j.2153-3490.1976.tb00696.x.

Hay, C. C., E. Morrow, R. E. Kopp, and J. X. Mitrovica, 2015: Probabilistic reanalysis of twentieth-century sea-level rise. Nature, 517, 481-484, doi:10.1038/nature14093.

Hirst, A. C., and J. Godfrey, 1993: The role of Indonesian Throughflow in a global ocean GCM. J. Phys. Oceanogr., 23, 1057-1086, doi:10.1175/1520-0485(1993)023<1057:TROITI >2.0.CO;2.

Jia, F., L. Wu, and B. Qiu, 2011: Seasonal modulation of eddy kinetic energy and its formation mechanism in the southeast Indian Ocean. J. Phys. Oceanogr., 41, 657-665, doi:10.1175/ 2010JPO4436.1.

Kalnay, E., and Coauthors, 1996: The NCEP/NCAR 40-Year Reanalysis Project. Bull. Amer. Meteor. Soc., 77, 437-471, doi:10.1175/1520-0477(1996)077<0437:TNYRP>2.0.CO;2.

Kara, A. B., H. E. Hurlburt, and A. J. Wallcraft, 2005: Stabilitydependent exchange coefficients for air-sea fluxes. J. Atmos. Oceanic Technol., 22, 1080-1094, doi:10.1175/JTECH1747.1.

Kenigson, J. S., and W. Han, 2014: Detecting and understanding the accelerated sea level rise along the east coast of the United States during recent decades. J. Geophys. Res. Oceans, 119, 8749-8766, doi:10.1002/2014JC010305.

Kessler, W. S., and R. Kleeman, 2000: Rectification of the MaddenJulian oscillation into the ENSO cycle. J. Climate, 13, 3560-3575, doi:10.1175/1520-0442(2000)013<3560:ROTMJO>2.0.CO;2.

Klein, S. A., B. J. Soden, and N. C. Lau, 1999: Remote sea surface temperature variations during ENSO: Evidence for a tropical atmospheric bridge. J. Climate, 12, 917-932, doi:10.1175/ 1520-0442(1999)012<0917:RSSTVD > 2.0.CO;2.

Köhl, A., and D. Stammer, 2008: Decadal sea level changes in the 50-year GECCO ocean synthesis. J. Climate, 21, 1876-1890, doi:10.1175/2007JCLI2081.1.

Kondrashov, D., and P. Berloff, 2015: Stochastic modeling of decadal variability in ocean gyres. Geophys. Res. Lett., 42, 15431553, doi:10.1002/2014GL062871. 
Lee, S.-S., and Coauthors, 2012: Interdecadal changes in the storm track activity over the North Pacific and North Atlantic. Climate Dyn., 39, 313-327, doi:10.1007/s00382-011-1188-9.

Lee, T., 2004: Decadal weakening of the shallow overturning circulation in the south Indian Ocean. Geophys. Res. Lett., 31, L18305, doi:10.1029/2004GL020884.

— , and M. J. McPhaden, 2008: Decadal phase change in largescale sea level and winds in the Indo-Pacific region at the end of the 20th century. Geophys. Res. Lett., 35, L01605, doi:10.1029/2007GL032419.

_ I. Fukumori, and B. Tang, 2004: Temperature advection: Internal versus external processes. J. Phys. Oceanogr., 34, 1936-1944, doi:10.1175/1520-0485(2004)034<1936:TAIVEP>2.0.CO;2.

Le Traon, P., F. Nadal, and N. Ducet, 1998: An improved mapping method of multisatellite altimeter data. J. Atmos. Oceanic Technol., 15, 522-534, doi:10.1175/1520-0426(1998)015<0522: AIMMOM $>2.0 . \mathrm{CO} ; 2$.

Levitus, S., J. I. Antonov, T. P. Boyer, H. E. Garcia, and R. A. Locarnini, 2005: Linear trends of zonally averaged thermosteric, halosteric, and total steric sea level for individual ocean basins and the world ocean, (1955-1959)-(1994-1998). Geophys. Res. Lett., 32, L16601, doi:10.1029/2005GL023761.

Li, Y., W. Han, T. Shinoda, C. Wang, R. C. Lien, J. N. Moum, and J. W. Wang, 2013: Effects of the diurnal cycle in solar radiation on the tropical Indian Ocean mixed layer variability during wintertime Madden-Julian oscillations. J. Geophys. Res. Oceans, 118, 4945-4964, doi:10.1002/jgrc.20395.

,,,---- M. Ravichandran, and J.-W. Wang, 2014: Revisiting the wintertime intraseasonal SST variability in the tropical south Indian Ocean: Impact of the ocean interannual variation. J. Phys. Oceanogr., 44, 1886-1907, doi:10.1175/ JPO-D-13-0238.1.

, —, and T. Lee, 2015: Intraseasonal sea surface salinity variability in the equatorial Indo-Pacific Ocean induced by Madden-Julian oscillations. J. Geophys. Res. Oceans, 120, 2233-2258, doi:10.1002/2014JC010647.

Llovel, W., and T. Lee, 2015: Importance and origin of halosteric contribution to sea level change in the southeast Indian Ocean during 2005-2013. Geophys. Res. Lett., 42, 1148-1157, doi:10.1002/2014GL062611.

Locarnini, R. A., A. V. Mishonov, J. I. Antonov, T. P. Boyer, H. E. Garcia, O. K. Baranova, M. M. Zweng, and D. R. Johnson, 2010: Temperature. Vol. 1, World Ocean Atlas 2009, S. Levitus, Ed., NOAA Atlas NESDIS 68, 184 pp.

Luo, J.-J., W. Sasaki, and Y. Masumoto, 2012: Indian Ocean warming modulates Pacific climate change. Proc. Natl. Acad. Sci. USA, 109, 18 701-18706, doi:10.1073/pnas.1210239109.

Lutjeharms, J. R. E., and R. C. Van Ballegooyen, 1988: The retroflection of the Agulhas Current. J. Phys. Oceanogr., 18, 1570-1583, doi:10.1175/1520-0485(1988)018<1570: TROTAC $>2.0 . \mathrm{CO} ; 2$.

Madden, R. A., and P. R. Julian, 1971: Detection of a 40-50 day oscillation in the zonal wind in the tropical Pacific. J. Atmos. Sci., 28, 702-708, doi:10.1175/1520-0469(1971)028<0702: DOADOI $>2.0 . \mathrm{CO} ; 2$.

Masumoto, Y., and G. Meyers, 1998: Forced Rossby waves in the southern tropical Indian Ocean. J. Geophys. Res., 103, 27589 27 602, doi:10.1029/98JC02546.

Merrifield, M. A., 2011: A shift in western tropical Pacific sea level trends during the 1990s. J. Climate, 24, 4126-4138, doi:10.1175/ 2011JCLI3932.1.

Meyssignac, B., M. Becker, W. Llovel, and A. Cazenave, 2012: An assessment of two-dimensional past sea level reconstructions over 1950-2009 based on tide-gauge data and different input sea level grids. Surv. Geophys., 33, 945-972, doi:10.1007/ s10712-011-9171-x.

Moore, A. M., and R. Kleeman, 1999: Stochastic forcing of ENSO by the intraseasonal oscillation. J. Climate, 12, 1199-1220, doi:10.1175/1520-0442(1999)012<1199:SFOEBT>2.0.CO;2.

Murakami, T., and M. Frydrych, 1974: On the preferred period of upper wind fluctuations during the summer monsoon. J. Atmos. Sci., 31, 1549-1555, doi:10.1175/1520-0469(1974)031<1549: OTPPOU $>2.0 . \mathrm{CO} ; 2$.

Nakamura, H., T. Sampe, Y. Tanimoto, and A. Shimpo, 2004: Observed associations among storm tracks, jet streams and midlatitude oceanic fronts. Earth's Climate, C. Wang et al., Eds., Amer. Geophys. Union, 329-345.

Nidheesh, A. G., M. Lengaigne, J. Vialard, A. S. Unnikrishnan, and H. Dayan, 2013: Decadal and long-term sea level variability in the tropical Indo-Pacific Ocean. Climate Dyn., 41, 381-402, doi:10.1007/s00382-012-1463-4.

Palanisamy, H., A. Cazenave, B. Meyssignac, L. Soudarin, G. Wöppelmann, and M. Becker, 2014: Regional sea level variability, total relative sea level rise and its impacts on islands and coastal zones of Indian Ocean over the last sixty years. Global Planet. Change, 116, 54-67, doi:10.1016/ j.gloplacha.2014.02.001.

Papa, F., F. Durand, W. B. Rossow, A. Rahman, and S. K. Bala, 2010: Satellite altimeter-derived monthly discharge of the Ganga-Brahmaputra River and its seasonal to interannual variations from 1993 to 2008. J. Geophys. Res., 115, C12013, doi:10.1029/2009JC006075.

Penland, C., and L. M. Hartten, 2014: Stochastic forcing of north tropical Atlantic sea surface temperatures by the North Atlantic Oscillation. Geophys. Res. Lett., 41, 2126-2132, doi:10.1002/2014GL059252.

Perigaud, C., and P. Delecluse, 1993: Interannual sea level variations in the tropical Indian Ocean from Geosat and shallow water simulations. J. Phys. Oceanogr., 23, 1916-1934, doi:10.1175/1520-0485(1993)023<1916:ISLVIT>2.0.CO;2.

Philander, S. G. H., 1983: El Niño Southern Oscillation phenomena. Nature, 302, 295-301, doi:10.1038/302295a0.

Potemra, J. T., and R. Lukas, 1999: Seasonal to interannual modes of sea level variability in the western Pacific and eastern Indian Oceans. Geophys. Res. Lett., 26, 365-368, doi:10.1029/ 1998GL900280.

Power, S., T. Casey, C. Folland, A. Colman, and V. Mehta, 1999: Inter-decadal modulation of the impact of ENSO on Australia. Climate Dyn., 15, 319-324, doi:10.1007/s003820050284.

Qiu, B., and S. Chen, 2012: Multidecadal sea level and gyre circulation variability in the northwestern tropical Pacific Ocean. J. Phys. Oceanogr., 42, 193-206, doi:10.1175/JPO-D-11-061.1. __ - — , L. Wu, and S. Kida, 2015: Wind- versus eddy-forced regional sea level trends and variability in the North Pacific Ocean. J. Climate, 28, 1561-1577, doi:10.1175/ JCLI-D-14-00479.1.

Rao, R., M. G. Kumar, M. Ravichandran, A. Rao, V. Gopalakrishna, and P. Thadathil, 2010: Interannual variability of Kelvin wave propagation in the wave guides of the equatorial Indian Ocean, the coastal Bay of Bengal and the southeastern Arabian Sea during 1993-2006. Deep-Sea Res. I, 57, 1-13, doi:10.1016/j.dsr.2009.10.008.

Rao, S. A., S. K. Behera, Y. Masumoto, and T. Yamagata, 2002: Interannual subsurface variability in the tropical Indian Ocean with a special emphasis on the Indian Ocean dipole. Deep-Sea Res. II, 49, 1549-1572, doi:10.1016/S0967-0645(01)00158-8. 
Rayner, N. A., D. E. Parker, E. B. Horton, C. K. Folland, L. V. Alexander, D. P. Rowell, E. C. Kent, and A. Kaplan, 2003: Global analyses of sea surface temperature, sea ice, and night marine air temperature since the late nineteenth century. J. Geophys. Res., 108, 4407, doi:10.1029/2002JD002670.

Rio, M. H., S. Guinehut, and G. Larnicol, 2011: New CNES-CLS09 global mean dynamic topography computed from the combination of GRACE data, altimetry, and in situ measurements J. Geophys. Res., 116, C07018, doi:10.1029/2010JC006505.

Saji, N., B. Goswami, P. Vinayachandran, and T. Yamagata, 1999: A dipole mode in the tropical Indian Ocean. Nature, 401, 360-363.

Sallenger, A. H., K. S. Doran, and P. A. Howd, 2012: Hotspot of accelerated sea-level rise on the Atlantic coast of North America. Nat. Climate Change, 2, 884-888, doi:10.1038/nclimate1597.

Schwarzkopf, F. U., and C. W. Böning, 2011: Contribution of Pacific wind stress to multi-decadal variations in upper-ocean heat content and sea level in the tropical south Indian Ocean. Geophys. Res. Lett., 38, L12602, doi:10.1029/2011GL047651.

Sérazin, G., T. Penduff, S. Gregorio, B. Barnier, J. Molines, and L. Terray, 2015: Intrinsic variability of sea-level from global $1 / 12^{\circ}$ ocean simulations: Spatiotemporal scales. J. Climate, 28, 4279-4292, doi:10.1175/JCLI-D-14-00554.1.

Shankar, D., and S. R. Shetye, 1999: Are interdecadal sea level changes along the Indian coast influenced by variability of monsoon rainfall? J. Geophys. Res., 104, 26031-26042, doi:10.1029/1999JC900218.

Siedler, G., M. Rouault, and J. Lutjeharms, 2006: Structure and origin of the subtropical south Indian Ocean Countercurrent. Geophys. Res. Lett., 33, L24609, doi:10.1029/2006GL027399.

Sprintall, J., and A. Révelard, 2014: The Indonesian Throughflow response to Indo-Pacific climate variability. J. Geophys. Res. Oceans, 119, 1161-1175, doi:10.1002/2013JC009533.

Stammer, D., and S. Hüttemann, 2008: Response of regional sea level to atmospheric pressure loading in a climate change scenario. J. Climate, 21, 2093-2101, doi:10.1175/2007JCLI1803.1.

— - A. Cazenave, R. M. Ponte, and M. E. Tamisiea, 2013: Causes for contemporary regional sea level changes. Annu. Rev. Mar. Sci., 5, 21-46, doi:10.1146/annurev-marine-121211-172406.

Sura, P., and C. Penland, 2002: Sensitivity of a double-gyre ocean model to details of stochastic forcing. Ocean Modell., 4, 327345, doi:10.1016/S1463-5003(02)00008-2.

- and M. Newman, 2008: The impact of rapid wind variability upon air-sea thermal coupling. J. Climate, 21, 621-637, doi:10.1175/2007JCLI1708.1.

_ - — and M. A. Alexander, 2006: Daily to decadal sea surface temperature variability driven by state-dependent stochastic heat fluxes. J. Phys. Oceanogr., 36, 1940-1958, doi:10.1175/JPO2948.1.

Suzuki, T., and M. Ishii, 2015: Interdecadal baroclinic sea level changes in the North Pacific based on historical ocean hydrographic observations. J. Climate, 28, 4585-4594, doi:10.1175/ JCLI-D-13-00103.1.

Timmermann, A., S. McGregor, and F.-F. Jin, 2010: Wind effects on past and future regional sea level trends in the southern IndoPacific. J. Climate, 23, 4429-4437, doi:10.1175/2010JCLI3519.1.
Tozuka, T., T. Yokoi, and T. Yamagata, 2010: A modeling study of interannual variations of the Seychelles dome. J. Geophys. Res., 115, C04005, doi:10.1029/2009JC005547.

Trenary, L. L., and W. Han, 2008: Causes of decadal subsurface cooling in the tropical Indian Ocean during 1961-2000. Geophys. Res. Lett., 35, L17602, doi:10.1029/2008GL034687.

$\ldots$, and _ 2012: Intraseasonal-to-interannual variability of south Indian Ocean sea level and thermocline: Remote versus local forcing. J. Phys. Oceanogr., 42, 602-927, doi:10.1175/ JPO-D-11-084.1.

, and - 2013: Local and remote forcing of decadal sea level and thermocline depth variability in the south Indian Ocean. J. Geophys. Res. Oceans, 118, 381-398, doi:10.1029/ 2012JC008317.

Tsai, P. T. H., J. J. O'Brien, and M. E. Luther, 1992: The 26-day oscillation observed in the satellite sea surface temperature measurements in the equatorial western Indian Ocean. J. Geophys. Res., 97, 9605-9618, doi:10.1029/91JC03162.

Unnikrishnan, A., and D. Shankar, 2007: Are sea-level-rise trends along the coasts of the north Indian Ocean consistent with global estimates? Global Planet. Change, 57, 301-307, doi:10.1016/j.gloplacha.2006.11.029.

van Ballegooyen, R. C., M. L. Gründlingh, and J. R. E. Lutjeharms, 1994: Eddy fluxes of heat and salt from the southwest Indian Ocean into the southeast Atlantic Ocean: A case study. J. Geophys. Res., 99, 14 053-14 070, doi:10.1029/94JC00383.

Wallcraft, A. J., E. J. Metzger, and S. N. Carroll, 2009: Software design description for the Hybrid Coordinate Ocean Model (HYCOM) version 2.2. Naval Research Laboratory Tech. Rep. NRL/MR/7320-09-9166, 157 pp.

Webster, P. J., A. M. Moore, J. P. Loschnigg, and R. R. Leben, 1999: Coupled ocean-atmosphere dynamics in the Indian Ocean during 1997-98. Nature, 401, 356-360, doi:10.1038/43848.

Wijffels, S., and G. Meyers, 2004: An intersection of oceanic waveguides: Variability in the Indonesian Throughflow region. J. Phys. Oceanogr., 34, 1232-1253, doi:10.1175/ 1520-0485(2004)034<1232:AIOOWV>2.0.CO;2.

Willis, J., D. Chambers, C. Kuo, and C. Shum, 2010: Global sea level rise: Recent progress and challenges for the decade to come. Oceanography, 23, 26-35, doi:10.5670/oceanog.2010.03.

Wirth, A., J. Willebrand, and F. Schott, 2002: Variability of the Great Whirl from observations and models. Deep-Sea Res. Part II, 49, 1279-1295, doi:10.1016/S0967-0645(01)00165-5.

Xie, S.-P., H. Annamalai, F. A. Schott, and J. P. McCreary, 2002: Structure and mechanisms of south Indian Ocean climate variability. J. Climate, 15, 864-878, doi:10.1175/ 1520-0442(2002)015<0864:SAMOSI >2.0.CO;2.

Yu, W., B. Xiang, L. Liu, and N. Liu, 2005: Understanding the origins of interannual thermocline variations in the tropical Indian Ocean. Geophys. Res. Lett., 32, L24706, doi:10.1029/ 2005 GL024327.

Zhuang, W., M. Feng, Y. Du, A. Schiller, and D. Wang, 2013: Lowfrequency sea level variability in the southern Indian Ocean and its impacts on the oceanic meridional transports. J. Geophys. Res. Oceans, 118, 1302-1315, doi:10.1002/jgrc.20129. 